\title{
Corticostriatal deficits underlying cognitive impairments induced by fetal exposure to alcohol
}

\author{
Authors: Sebastiano Bariselli ${ }^{1,2}$ and David M. Lovinger ${ }^{1} \S \S$ \\ 1. National Institute on Alcohol Abuse and Alcoholism (NIAAA), 5625 Fishers Lane, Bethesda, MD
} (20892-941)

2. Center on Compulsive Behaviors, Intramural Research Program, National Institute of Health (NIH), Bethesda, MD, United States

Corresponding author: lovindav@willco.niaaa.nih.gov

Funding: SB is supported by the postdoc.mobility fellowship \#183841 from the Swiss National Science Foundation (SNSF), the Laboratory for Integrative Neuroscience (LIN) at NIAAA-NIH and the NIH Center on Compulsive Behaviors (CCB).

Conflict of interest: The authors declare no conflict of interest.

\begin{abstract}
The term Fetal Alcohol Spectrum Disorder (FASD) includes a group of diseases caused by fetal exposure to alcohol (FAE). FASD patients display heterogenous socio-emotional and cognitive deficits, particularly in the domain of executive function, which share symptoms with other neuropsychiatric disorders. Despite the availability of several preclinical models, the developmental brain defects causally linked to behavioral deficits induced by FAE remain poorly understood. Here, we first review the FAEinduced synaptic and circuit impairments in mesocorticolimbic areas involved in social and motor behaviors. Then, we consider the effects of FAE on cortical excitation/inhibition balance and its impact on both corticostriatal pathway function and cognitive abilities. In particular, we propose three non-mutually exclusive circuit models of corticostriatal dysfunctions to account for some of the FAE-induced cognitive deficits. One model posits that associative-sensorimotor imbalance causes hyper goal-directed behavior and a second model implies that alteration of prefrontal-striatal behavioral suppression circuits results in the loss of behavioral inhibition. A third model suggests that local striatal circuit deficits affect striatal neuronal ensemble function to impair action selection and performance. Finally, we discuss how pre-clinical approaches suggest potential rescue strategies for neuronal circuit defects in FASD patients.
\end{abstract}




\section{Table of Contents}

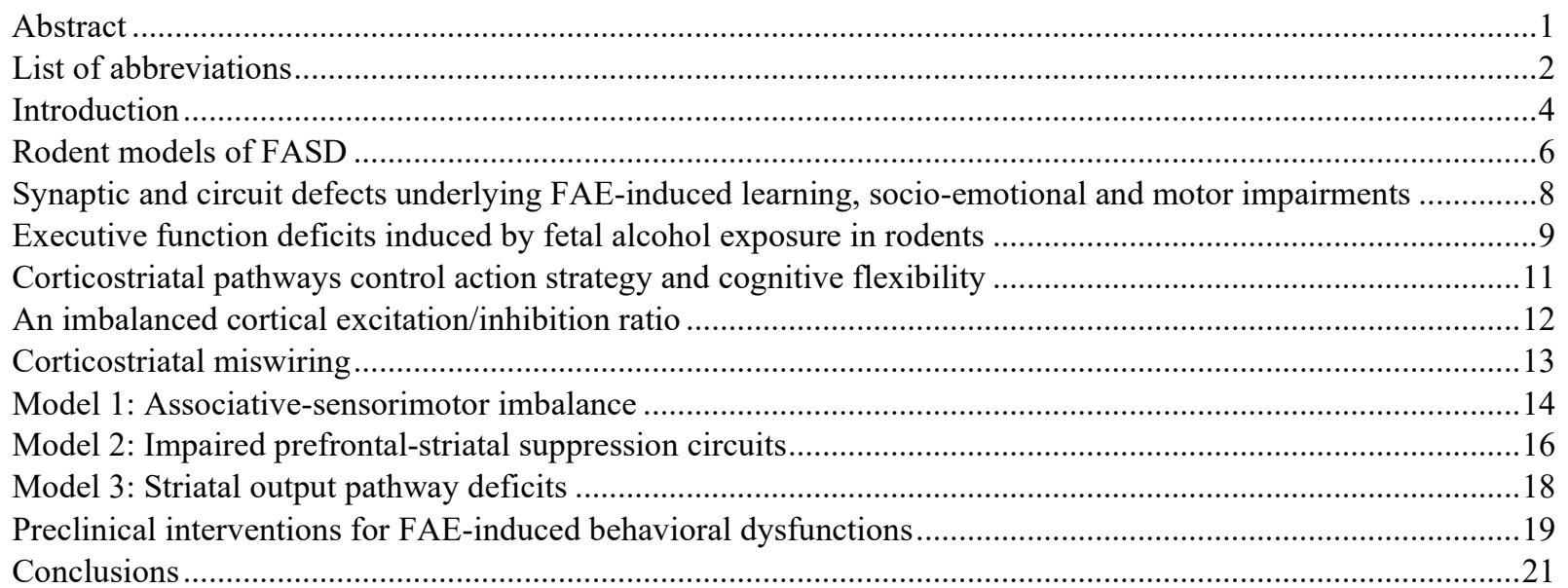

\section{List of abbreviations}

$\begin{array}{ll}\text { FASD } & \text { Fetal Alcohol Spectrum Disorder } \\ \text { FAS } & \text { Fetal Alcohol Syndrome } \\ \text { FAE } & \text { Fetal Alcohol Exposure } \\ \text { CDC } & \text { Centers for Disease Control and Prevention } \\ \text { ADHD } & \text { Attention Deficit Hyperactivity Disorder } \\ \text { OCD } & \text { Obsessive Compulsive Disorder } \\ \text { BAC } & \text { Blood Alcohol Concentration } \\ \text { CIE } & \text { Chronic Intermittent Ethanol } \\ \text { HFS } & \text { High Frequency Stimulation } \\ \text { LTP } & \text { Long-Term Potentiation } \\ \text { EPSP } & \text { Excitatory Post-Synaptic Potential } \\ \text { NMDAR } & \text { N-Methyl D-aspartic Acid Receptor } \\ \text { DG } & \text { Dentate Gyrus } \\ \text { VTA } & \text { Ventral Tegmental Area } \\ \text { AMPAR } & \alpha \text {-Amino-3-hydroxy-5-Methyl-4-isoxazolePropionic Acid Receptor } \\ \text { eCB } & \text { endoCannaBinoid } \\ \text { LTD } & \text { Long-term Depression } \\ \text { MSN } & \text { Medium Spiny Neuron } \\ \text { D1R } & \text { Dopamine Receptor 1 } \\ \text { D2R } & \text { Dopamine Receptor 2 } \\ \text { OFC } & \text { Orbitofrontal Cortex } \\ \text { PFC } & \text { Prefrontal Cortex (1,2) } \\ \text { DLS } & \text { DorsoLateral Striatum } \\ \text { DMS } & \text { DorsoMedial Striatum } \\ & \end{array}$


M1

primary Motor Cortex 
"The root of the problem is not neglect or abuse, although for many, disruptive families have compounded their problems. They [people with FASD] live in self-perpetuating ignorance, poverty, and crime because they came into the world with permanent neurological damage that could have been prevented."

- From Damaged Angels, Bonnie Buxton (2004)

\section{Introduction}

The teratogenic effects of ethanol (EtOH) manifest as highly prevalent and heterogeneous somatic abnormalities as well as lifelong neurobehavioral deficits (1-3), collectively known as "fetal alcohol spectrum disorder" (FASD) (Diagnostic and Statistical Manual of Mental Disorders 5; American Psychiatry Association, pp. 86, 798-801, Washington DC). FASD includes fetal alcohol syndrome (FAS), partial FAS, alcohol-related birth defects, alcohol-related neurodevelopmental disorder and neurobehavioral disorder associated with prenatal alcohol exposure. Altogether these disorders affect 1 in 20 children (2). In the US, the estimated economic burden of $\$ 4$ billion/year (4) is largely due to the underdiagnosis of the disease (5), the absence of a definitive treatment (6), adverse postnatal environments (7) and the protraction of the neurobehavioral symptoms into adult patients (8-16), which often necessitate assisted living. In fact, according to the Centers for Disease Control and Prevention (CDC, https:/www.cdc.gov/ncbddd/fasd/index.html), FASD adults have, among others, troubles with the law, inappropriate sexual conduct, drug abuse and difficulties in maintaining a job.

Over the years, several rodent models of FASD have been developed to better understand the brain deficits underlying FAE-induced behavioral impairments. Here, we discuss pre-clinical studies that focus on the neural circuit and synaptic dysfunctions involved in socio-emotional, motor and cognitive deficits induced by FAE. In particular, because of their vulnerability to the teratogenic effects of alcohol, we examine the effects of FAE on synaptic and neuronal function within corticostriatal circuits. First, we explore the idea that altered excitatory/inhibitory balance within cortical networks affects corticostriatal pathway functions. Then, we propose three different models of circuit impairments to account for the FAEinduced executive function deficits. The first model involves imbalanced function of associativesensorimotor pathways that would favor goal-directed behavior, impair habit formation and preclude the formation or the updating of novel action-outcome associations. The second model posits that deficits in prefrontal-striatal circuits deputed to the suppression of behavioral programs promote action repetition and impair reversal learning. A third model proposes that impaired action performance originates from dysfunctions in striatal output pathways. Importantly, these models are not mutually exclusive and might emerge from complex interactions between cortical input, dopaminergic signaling and local GABAergic FAE-induced deficits. Finally, we discuss pre-clinical studies testing potential therapeutic approaches to 
ameliorate aberrant behavioral traits and neurophysiological deficits induced by exposure to ethanol during development.

\section{The socio-emotional and cognitive deficits caused by fetal exposure to alcohol}

The first cases of FAS were clinically described almost 50 years ago (17). Besides the consequences on somatic and anatomical development (18), fetal alcohol exposure (FAE) particularly impairs socioemotional processes. Socio-emotional dysfunctions span the range from hyper-irritability to heightened aggression (19,20), impaired recognition of social cues and impoverished interpersonal skills $(14,21)$ during infancy and adolescence. Further, adults often display inappropriate maternal and sexual behavior $(14,22)$ and unlawful conduct.

In addition to social deficits, FAE impairs "executive functions", which are a set of cognitive abilities available to an individual to reach a desired goal (23). They include the ability to focus attention, select actions, inhibit competing behavioral patterns, and the ability to learn and retain cue/action-outcome associations to generate goal-directed behavioral responses. Once learned, those responses become automatized, or habitual. This allows for the formation of novel action-outcome associations and behavioral adaptations in the face of changing circumstances (24), a process described as cognitive flexibility. EtOH exposure during pregnancy has dramatic consequences on all these aspects of executive function. In fact, FASD symptoms include reduced attention in complex tasks and spatial working memory (25), poor action planning $(26,27)$, which might be precipitated by low

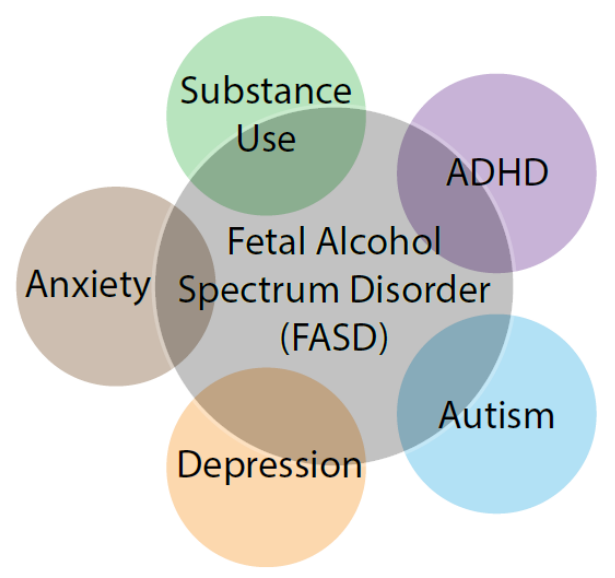

Figure 1. FASD co-morbidities. FASD shares clinical symptoms with other neuropsychiatric disorders, including substance abuse, attention deficits, hyperactivity, anxiety, depression and social deficits. intelligence (28), variable degrees of hyperactivity (9) and poor response inhibition (27,29). Cognitive flexibility is also profoundly impaired in both FASD children $(26,27,30,31)$ and adults (10). Moreover, EtOH exposure affects specific aspects of learning: FASD patients display difficulties in memorization rather than information retrieval $(16,32,33)$ and deficits in declarative, rather than procedural, memory (34). Although several rodent models of fetal alcohol exposure (FAE) have been developed over the years (35), direct links between neuronal circuits, cognitive and socio-emotional impairments remain largely unexplored (36).

This might be particularly relevant, as a thorough understanding of the defects in brain pathways that control executive function and socio-emotional defects might support effective therapeutic interventions for FASD patients. 
The cognitive and socio-emotional deficits observed in FASD patients often resemble symptoms of other neuropsychiatric disorders (37,38) (Figure 1) and can confound the FASD diagnosis (39). In particular, preclinical and clinical studies reported that impulsivity and hyperactivity traits appear in both FASD and attention deficit hyperactivity disorder (ADHD) (40). Obsessive-compulsive disorder (OCD) (37) and inappropriate social behavior (41), reminiscent of autism, are other secondary outcomes associated with fetal exposure to alcohol. Additionally, anxiety, depression, suicidal thoughts and drug use disorders often co-occur in patients with FASD (42). All these shared psychiatric symptoms indicate that similar neural circuit defects underlie comorbid neuropsychiatric disorders and that the investigation of brain maladaptations in one disease would be helpful to better understand a disorder with a shared symptomatology. This idea also motivates the identification of novel therapeutic interventions that, instead of curing one disorder, would treat a set of behavioral symptoms occurring in multiple diseases (Research Domain Criteria framework, NIMH). In this framework, the use of animal models of FASD might help to clarify the neuronal circuit deficits induced by fetal exposure to ethanol but also other neurodevelopmental disorders. The same approach can be applied to the identification of circuit-based rescue strategies for cognitive and socio-emotional deficits of FASD animal models. Considering that developmental exposure to alcohol impairs multiple aspects of behavior, it has been suggested that FAE might cause specific circuit and synaptic dysfunctions in brain regions deputed to the control of those behavioral traits (43). In particular, while hippocampal, mesolimbic, motor cortex and cerebellum deficits might underlie spatial learning, socio-emotional and motor behavior impairments, executive function deficits might result from synaptic and circuit dysfunctions in corticostriatal networks.

\section{Rodent models of FASD}

Animal models of fetal alcohol exposure (FAE) with face, construct and predictive validity must consider the timing and the amount of alcohol exposure, which greatly impacts blood alcohol concentration (BAC). In humans, some women unaware of their pregnancy status tend to consume large quantities of alcohol in a limited amount of time (binge drinking) and, in about $90 \%$ of the cases, drinking stops after pregnancy has been ascertained (44). However, psychological, psychiatric and environmental risk factors might promote binge-like drinking throughout pregnancy, the pattern of alcohol consumption most associated with a FASD diagnosis (45).

EtOH exerts its teratogenic effects on neural functions by interfering with the various stages of brain development (46). When alcohol is introduced into the body, BAC rises and EtOH enters fetal circulation via the placenta (47). EtOH metabolites, including fatty acid ethyl esters, are expelled in the meconium (48) and their levels reflect the pattern of alcohol ingestion during pregnancy (49). This is particularly relevant because EtOH exposure modalities seem to determine FASD severity: while early and 
repeated exposures are the most detrimental, even one single alcohol exposure causes neurological damage (50-53). As the fetus goes through various stages of development, the timing of exposure to alcohol also determines FASD symptomatology (45). In particular, EtOH has been shown to alter various stages of brain formation and maturation (50): from neurogenesis (51), neuronal proliferation and migration $(52,53)$, to synaptic formation and remodeling. Moreover, the amount of consumed EtOH affects BAC and impacts anatomical and behavioral function. For example, binge-drinking of alcohol could result in BAC equal or higher than $200 \mathrm{mg} / \mathrm{dL}$ (54). In this case, the probability of FASD diagnosis for the new-born is at its highest $(45,54,55)$, even though moderate alcohol ingestion has negative consequences on cognitive function as well (56). Other than dose, timing and modality of EtOH exposure, preclinical models of FAE need to consider the various possible routes of alcohol administration, which greatly influence BAC, and the postnatal maturation of brain circuits (57-59). In particular, rodent pregnancy is considerably shorter than human gestation and, while in the latter the period of brain development is almost complete at birth, this process continues outside of the uterus for about 7-10 days in rodents (57). Thus, it is not rare to find preclinical studies that extend or start FAE during postnatal periods.

In laboratory settings, ingestion of alcohol can be achieved by inducing voluntary drinking of a sweetened ethanol-containing solution before and during gestation (60) or by feeding pregnant females with an ethanol-enriched liquid diet (61). Voluntary drinking allows for moderate and protracted alcohol ingestion (with BAC at $50-150 \mathrm{mg} / \mathrm{dL}$ ) (60), but it poses some difficulties in controlling EtOH levels over time, partly because of the aversive properties of EtOH in rodents (62). The most reliable ways to control $\mathrm{BAC}$ are single or repeated intraperitoneal (i.p.) injections of $\mathrm{EtOH}$, which allow for a binge-like surge (BAC: $>200 \mathrm{mg} / \mathrm{dL}$ ) of circulating alcohol (63). However, injections are not the typical route of exposure and might lead to non-physiological increases of ethanol into fetal circulation (35). A binge-like consumption of alcohol in rodents can also be obtained by intragastric intubation (64-66), which induces significant surges of BAC (300-400 mg/dL) but negatively affects the well-being of the pregnant females. Lastly, chronic intermittent ethanol (CIE) exposure, which consists in cyclic periods of exposure to and withdrawal from EtOH vapor (67), induces and mimics alcohol abuse in adult rodents (68). Maintaining EtOH levels at 15-20 mg/L of air in the vapor chamber leads to stable and relatively high BAC (above 175 $\mathrm{mg} / \mathrm{dL}$ ), with a peak higher than $200 \mathrm{mg} / \mathrm{dL}$ (69). A great advantage of this method is that EtOH exposure can be protracted after birth as pups can be transferred with the dam in the vapor chamber, with minimal amount of stress and handling. On the other hand, inhalation is not the usual route of alcohol consumption and might irritate the respiratory tract (35), which could in turn act as a stressor. Thus, although each of those EtOH exposure protocols needs careful consideration, they provide useful pre-clinical models to study the behavioral deficits and the underlying brain dysfunctions induced by fetal alcohol exposure. 


\section{Synaptic and circuit defects underlying FAE-induced learning, socio-emotional and motor impairments}

Children and adults affected by FASD exhibit brain abnormalities, including microcephaly and reduction in grey/white matter volume $(70,71)$. Functional imaging studies further revealed that FASD patients display deficits in brain regions, including hippocampus, amygdala, basal ganglia and cerebellum, which in some cases correlate with symptom severity (72). Similarly, pre-clinical research has focused on investigating the cellular and synaptic deficits in brain areas that might underlie FAE symptoms. For example, given the involvement of hippocampal circuits in spatial navigation, FAE-induced spatial learning impairments might derive from hippocampal dysfunctions. In fact, it has been shown that prenatal alcohol exposure, via EtOH liquid diet or oral gavage, attenuated high-frequency stimulation (HFS)-induced longterm potentiation (LTP) of population responses in the CA1 region of both adult and adolescent rats $(73,74)$. However, EtOH exposure limited to the first post-natal days spared excitatory postsynaptic potential (EPSP) LTP in CA1 neurons (75). Moreover, when ethanol exposure starts nine-days after the beginning of pregnancy, LTP in CA1 region is preserved at low-, or barely affected by high-, concentration of ethanol (76). These findings indicate that the early stage of brain development might be a critical period of heightened vulnerability to the deleterious effects of alcohol on hippocampal synaptic plasticity. This hypothesis has been recently challenged by the evidence that a single early adolescence ethanol exposure alters NMDAR (N-methyl d-aspartic acid receptor)-dependent LTP while leaving NMDAR-independent LTP intact (77). Thus, EtOH retains some teratogenic effects on excitatory CA1 synapse function, and perhaps other synapses, even at later stages of synaptic maturation.

While the deleterious effects of FAE on synaptic plasticity of perforant pathway to dentate gyrus (DG) inputs are sensitive to the timing of exposure as in CA1 hippocampal neurons, they appear to be sexually dimorphic. In adult male rats, although short exposure to EtOH does not affect synaptic potentiation in vivo (78), prolonged FAE deteriorates perforant pathway plasticity $(79,80)$. Deficits in tetanic stimulation-induced release of D-aspartate in DG slice preparations after FAE confirm these findings $(79,81)$. On the contrary, in adult females LTP is intact (80) and even enhanced in early adults exposed to EtOH during late developmental stages (78). The sex-specific effects on synaptic plasticity are corroborated by sexually dimorphic transcriptional FAE-induced modifications in hippocampal gene expression (82). However, the apparent sexual dimorphism of LTP deficits in the DG are challenged by slice recordings showing that FAE attenuates LTP in both sexes and LTP can be reinstated with longer stimulation protocols in adolescent rats (83). Altogether, these studies indicate that the attenuation of LTP might be the main consequence of FAE at perforant pathway synapses. However, further experiments are required to clarify the genetic, environmental, synaptic and molecular mechanisms underlying the sex-, time- and agedependent deficits induced by FAE. 
Reward-seeking and social behavior depend on meso-cortico-limbic system function (84), thus the FAE-induced impairments in these domains might derive from neuronal defects in the ventral tegmental area (VTA) and amygdala circuits. In fact, similarly to prenatal cocaine exposure and genetic dysfunctions altering glutamatergic synapse maturation $(85,86)$, FAE strengthens excitatory inputs onto dopaminergic neurons of the ventral tegmental area (VTA) and increases the expression of GluA2-lacking AMPARs (87). These non-canonical AMPARs promote forms of anti-hebbian synaptic potentiation $(85,88)$, which are also reported following FAE (87). Concomitantly, deregulated endocannabinoid (eCB) signaling alters presynaptic glutamate release properties and attenuates eCB-dependent long-term depression (LTD) (89). Thus, the loss and the gain of depression and potentiation plasticity mechanisms, respectively, may result in an over-responsivity of VTA dopamine neurons to glutamatergic inputs and set the basis for the enhanced amphetamine-seeking behavior observed in FAE rat offspring $(87,89)$. Corroborating evidence suggests that, despite reduced hyperpolarization-induced cationic currents and up-regulated somato-dendritic D2R function, excitatory input and depolarization block deficits underlie the reduced firing frequency of VTA DA neurons in vivo following FAE (90). Similar to the VTA, prenatal alcohol exposure attenuates GABAergic tone and enhances LTP induced by HFS in the cortico-amygdala pathway (91), pointing to an enhanced excitatory plasticity induced by FAE in the amygdala.

Hyperactivity and altered coordination might stem from impaired cerebellar and cortico-striatal circuit function. In the cerebellum of adolescent mice, FAE reduces neuronal excitability, excitatory input strength as well as the number of Purkinje cells (92). However, prenatal ethanol exposure concomitantly promotes LTP at parallel fiber cerebellar inputs. This is thought to be a synaptic mechanism potentially underlying the increased firing activity of Purkinje cells, which is associated with motor skill learning disabilities (92). Similarly, it has been shown that EtOH exposure alters the genetic profile and the excitability of layer II/III neurons in the motor cortex, resulting in impairments in rotarod-based motor learning (93). Altogether, these studies highlight the heterogeneous effects of EtOH exposure on synaptic function, they further suggest that FAE increases excitatory synaptic function in VTA, amygdala and cerebellum to impair drug seeking behavior, sociability and motor learning in the offspring.

\section{Executive function deficits induced by fetal alcohol exposure in rodents}

The neurobehavioral studies conducted in different FAE models recapitulated most of the executive function impairments observed in FASD patients (94). A series of behavioral experiments revealed attention deficits in FAE adult rats, as evidenced by increased reaction times, augmented rates of false alarms and reduced response accuracy $(95,96)$. Furthermore, in a delayed matching-to-place Morris Water Maze, in which animals learn to find a hidden platform, FAE male rats performed poorly at longer-, but not shorter, inter-trial intervals (97). This evidence points to impaired spatial working memory, but intact 
learning at sufficiently brief inter-training intervals. The effects of FAE on learning can also be studied throughout life, starting as early as postnatal day 1 (P1) (98). The use of EtOH as a reinforcer revealed an increased acquisition together with a reduced extinction $(98,99)$ of operant responding at infancy. Similarly, FAE increases operant responding for both EtOH and sucrose at adolescence $(100,101)$ and lever-pressing for low-doses of psychostimulants at adulthood (87). However, FAE does not affect other learning tasks, such as the acquisition of food-reward contingencies in the Y-maze (102) or spatial learning in the Morris and T Water Mazes $(103,104)$. Therefore, despite causing attention and working-memory deficits, FAE might increase reward sensitivity allowing, and in some cases enhancing, reward-seeking in operant tasks. These behavioral data also indicate that FAE might predispose to alcohol- and drug-seeking later in life, traits resembling the highly prevalent substance use and dependence observed in FASD patients (105).

The increased operant responding for substances of abuse and the enhanced perseverative operant responses suggest that FAE might affect goal-directed and/or habitual behavior. Recently, our laboratory tested this hypothesis by training FAE mice under random-ratio (RR) or random-interval (RI) reinforcement schedules to bias animals towards goal-directed or habitual instrumental responding, respectively (106). Although FAE mice increased lever pressing during RR training, they reduced operant responding following outcome devaluation suggesting an appropriate use of goal-directed strategies. However, these same mice retained a goal-directed pattern of responding following RI training, indicative of impaired habit formation (107). Interestingly, other studies reported that maladaptive perseverative responses underlie inflexible behavior upon changes in contextual associations. In fact, in the absence of overt learning deficits, FAE adult mice display enhanced reinstatement of previously extinguished responses (108). These impairments are associated with reversal learning deficits, indicative of altered cognitive flexibility, in both adolescent and adult FAE offspring (43,102,109-111). Again, these behavioral deficits provide a good parallel with behavioral inflexibility observed in FASD (105). The paradoxical FAE-induced deficits in both reversal learning, which suggests a more automatized behavioral responding, and habit formation, which instead points to a stronger reliance on goal-directed strategies, is intriguing. Here, we hypothesize that hyper goal-directed strategies based on previously learned action-outcome associations, and sensitive to the subjective value of a stimulus, would hinder the animal's ability to develop novel action-outcome associations, leading to inflexible behavior upon changes in external circumstances.

FASD neurobehavioral symptoms include reduced inhibition of behavioral responding, which might also underlie the heightened operant responding described above. Indeed, passive avoidance tasks, which assess the ability to constrain the natural tendency to explore novel environments, revealed altered response inhibition in adolescent FAE rodents (112), particularly in female offspring (113). Further, both adolescent and adult FAE rats display a hyper-active/hyper-exploratory phenotype, including increased 
nose-poking, head-dipping and locomotion (114) together with spatial perseveration in a Morris Water Maze task (103). Importantly, similar deficits in response inhibition and perseveration are frequently observed in FASD patients (105) and typically treated by using ADHD psychostimulant medications (https://www.cdc.gov/ncbddd/fasd/treatments.html\#Medication), highlighting both the construct and predictive validity of FAE animal models. These behavioral experiments suggest an alternative hypothesis to the hyper goal-directed idea described above. In fact, the enhanced operant responding and inflexibility traits might derive from an inability of FAE to generate appropriate behavioral inhibition, which could further preclude the formation of novel behavioral patterns upon changes in external circumstances. Thus, considering that different corticostriatal circuits contribute to these different aspects of executive function, we speculate that FAE-induced impairments in those pathways lead to cognitive function deficits.

\section{Corticostriatal pathways control action strategy and cognitive flexibility}

The neuronal network connecting different neocortical areas to the striatum, which is part of a subcortical group of nuclei collectively known as the basal ganglia, constitutes the cortico-striatal pathways $(115,116)$. In particular, neocortical areas send excitatory projections to the main class of neurons populating the striatum: the medium spiny neurons (MSNs; Figure 2a) (117). MSNs cluster in direct (projecting to the substantia nigra reticulata) and indirect (projecting to the globus pallidus) pathways, expressing dopamine 1 (D1R) or 2 (D2R) receptors, respectively (118). The neuromodulator dopamine, which is released by midbrain neurons, controls both the activity and synaptic plasticity at cortical inputs onto MSNs (119-121). MSNs regulate locomotion (122), action selection (123), goal-directed behavior and habit formation (106), all behavioral aspects altered by FAE. In particular, the reciprocal loops between associative and sensorimotor cortical areas to dorsal striatal regions (caudate and putamen) instruct the acquisition and performance of behavioral strategies (124,125). Goal-directed behavior, which drives the execution of an action to obtain a predicted outcome (also known as action-outcome strategy), relies on the function of the projections from associative (frontal) cortices, including the orbitofrontal (OFC) and the prefrontal cortex (PFC), to the dorsomedial striatum (DMS) $(125,126)$. Habitual behavior, which consists of more automatized actions triggered by external stimuli and reinforcement history (stimulus-response actions), relies on the projections from sensorimotor cortices, including the primary motor cortex (M1), to dorsolateral striatum (DLS) (125,126). Action-learning rapidly engages the PFC-DMS (associative) pathway, which is disengaged as learning proceeds (124). At the same time, M1-DLS pathway activation increases as the action execution becomes habitual (127). Thus, a dynamic engagement of these pathways occurs during the performance of everyday actions and its perturbations might lead to psychiatric disorders characterized by the loss of inhibitory control and altered habit formation, both traits displayed by FASD patients. Moreover, cognitive flexibility, defined as the ability to disengage from habitual responding and 
adapt action performance in the face of changing circumstances, relies on an intact functionality of OFCDMS circuits. In fact, OFC neurons track the value of a stimulus (128) and update novel cue-reward contingencies (129). Thus, specific deficits in cortico-striatal networks might underlie the disrupted executive function capabilities of both in FASD patients and pre-clinical models of FAE.

\section{An imbalanced cortical excitation/inhibition ratio}

Evidence of cortical thinning in pre- (motor) and post- (somatosensory) central areas and frontal lobes $(130,131)$, which encompass both the OFC and the PFC, support the hypothesis that altered corticostriatal networks impair executive function in FASD patients. Additionally, children and adolescents affected by FASD present connectivity dysfunctions in sensorimotor networks (132). Similarly, FAE rodents show neuroanatomical, cellular and functional alterations in OFC, PFC, somatosensory cortex, motor cortex and striatum from infancy to adulthood (133-136). Because of the role of frontal cortex in learning and behavioral flexibility (137), several studies investigated the function of excitatory and inhibitory neurons in PFC of FAE rodents. In the PFC, developmental alcohol exposure decreases spine

a
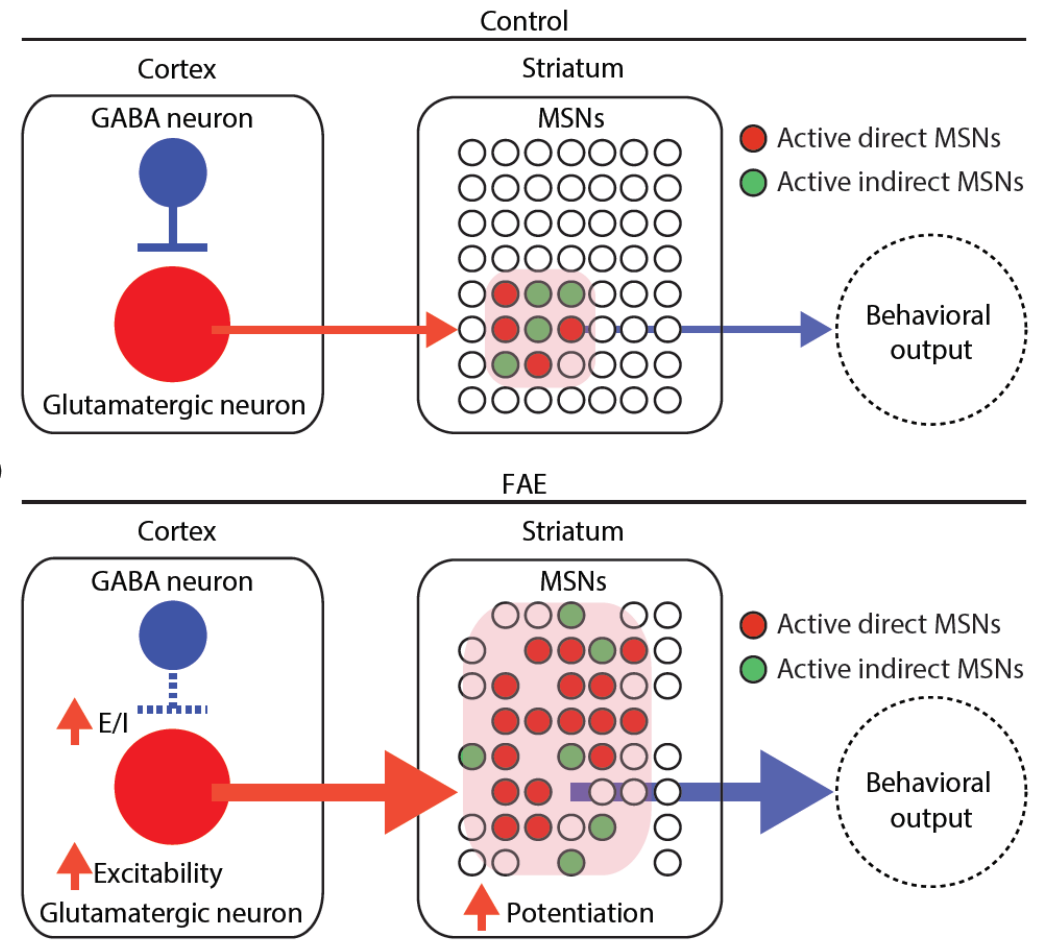

Figure 2. Excitatory/inhibitory imbalance and corticostriatal pathway dysfunctions following FAE. (a) Schematics of neocortical neurons projecting onto striatal regions to control the recruitment of downstream striatal MSNs. (b) FAE alters the excitatory/inhibitory (E/I) balance within cortical regions to increase the excitability of projecting neurons. The increased functional connectivity between cortical and striatal regions might then result in synaptic potentiation and aberrant recruitment of striatal neuron ensembles. density in layer II/III neurons (138) but enhances AMPAR function in pyramidal neurons of deeper cortical layers (96), which in turn send inputs to striatal regions (117). In Layer V/VI of the somatosensory cortex, an increase in both miniature and spontaneous excitatory postsynaptic currents (EPSCs), together with presynaptic facilitation, point to an increased excitatory drive on corticostriatal neurons (135).

In parallel, FAE alters the tangential migration of developing cortical GABAergic neurons (139) and alters their number in their target cortical areas (140-142). Interestingly, 
similar deficits in interneuron function contribute to the impaired excitation/inhibition balance (E/I) in animal models of autism (143) and might ultimately disrupt cortical neuron output in FAE offspring as well (Figure 2b). Corroborating evidence shows heightened coherence and hyper-excitability of piriform cortex-hippocampal networks upon cue-presentation, which seems to rely on aberrant excitatory synapse facilitation $(144,145)$. Similarly, FAE mice display enhanced functional connectivity between OFC and striatum during specific phases of reversal learning (146). It should be noted that FAE increases both the number of Calretinin-positive GABAergic interneurons and the amplitude of inhibitory post-synaptic currents in the OFC (147), highlighting potential differences in the effects of EtOH based on the timing of the exposure and the brain areas analyzed. Thus, the hypothesis of an impaired cortical E/I balance and its effects on downstream striatal neurons needs to be further explored and requires careful consideration of the FAE model and brain area analyzed.

\section{Corticostriatal miswiring}

The formation of cortico-striatal networks is a controlled sequence of embryonic and postnatal events, which starts with the invasion of the embryonic striatum (E12-E13) by cortical projection axons and terminates with the completion of synaptic maturation around P30 (148). Exposure to alcohol interferes with these processes, leading to cell loss, reduced dendritic complexity, decreased neuronal excitability, altered neuromodulation and impaired synaptic transmission. In particular, EtOH exposure during development reduces the size of the caudate nucleus in humans $(71,149)$ and a single EtOH injection during striatal synaptogenesis induces extensive apoptosis in the caudate-putamen striatal regions in mice (150). Moreover, FAE induces a significant reduction in dendritic complexity of GABAergic interneurons (151), which might also contribute to the reduced local GABAergic neuron function (107). EtOH exposure during pregnancy increases dendritic length (152) and produces sexually-dimorphic excitability deficits (153) in MSNs of the nucleus accumbens/ventral striatum. In the DMS, a striatal subregion functionally innervated by associative cortical inputs (127), FAE increases neuronal dendritic length, as well as amplitude and frequency of mEPSCs in direct pathway MSNs (154). In DLS, which is part of sensorimotor cortico-striatal loops (127), adolescent male offspring of ethanol-fed rat dams display heightened excitatory inputs and glutamate release probability (155). Moreover, FEA attenuates HFS-induced long-term potentiation (LTP) at cortico-striatal inputs during early adolescence, but promotes LTP at later stages of development, when HFS typically induces long-term depression (LTD) (155). Interestingly, D2R agonist application rescues HFS-induced LTD suggesting that FAE might promote aberrant forms of cortico-striatal maturation via dopamine signaling alterations.

Indeed, exposure to alcohol during development has been shown to impair dopamine signaling in the striatum, which can further contribute to corticostriatal input impairments. In monkeys, early and late 
gestational ethanol exposure decreases and increases striatal dopamine function, respectively (156). In rodents, FAE decreases the expression of D2R during adolescence but it also reduces D1R during both adolescence and adulthood. These effects are associated with diminished dopamine transporter function to decrease dopamine re-uptake and exacerbate the behavioral adaptations induced by psychostimulant exposure later in life (157). Moreover, those dopaminergic impairments seem to contribute to hyperactivity (158), a behavioral trait commonly observed in both FASD and ADHD patients. Finally, since dopamine has been shown to control corticostriatal input formation, maturation (120) and plasticity (121), dopaminergic deregulation might further contribute to the corticostriatal excitatory synaptic deficits observed in FAE mice.

The data described above corroborate the idea of FAE-induced enhancement of excitatory transmission and plasticity at corticostriatal synapses. Appropriate synaptic plasticity at different corticostriatal inputs underlies multiple aspects of behavior, including goal-directed (159) and habitual (160) processes, and it has been hypothesized to control the recruitment of neuronal clusters (or neuronal ensembles) to promote behavioral output (123). Thus, despite the cell loss due to apoptotic processes, the increased excitatory transmission, the loss of GABAergic function and the impaired dopamine signaling might increase the recruitment of striatal neuronal ensembles and alter behavioral responses in FAE mice (Figure 2b). Because the various corticostriatal loops control different aspects of action selection and performance, the elucidation of the FAE-induced neuronal defects occurring in discrete corticostriatal networks might help to establish a causal link between circuits and cognitive impairments.

\section{Model 1: Associative-sensorimotor imbalance}

A model of striatal action selection posits that a "go-circuit" might engage an associative pathway (OFC-DMS) during goal-directed actions (e.g. learning) and sensorimotor (M1-DLS) circuits during habitual behaviors (Figure 3). Thus, positive reinforcers would activate a goal- directed "go-circuit" and changes in outcome value would modulate its activity. The habitual execution of an action would instead recruit sensorimotor circuits and be less sensitive to changes in outcome value. In fact, impairments of the OFC-DMS (associative) pathway disrupt goal-directed behavior in favor of an over-reliance on habitual responding, which is insensitive to outcome devaluation $(106,159,161)$. Accordingly, activation of the OFC-DMS pathway promotes goal-directed behavior (159) while motor stereotypies rely on an increased functionality of motor areas in motor diseases (162). It has been shown that the FAE-induced enhancement of operant responding depends on a decreased function of parvalbumin-positive GABAergic interneurons (107), which leads to hyperexcitable MSNs in sensorimotor DLS (red square in Figure 3). However, while chemogenetic activation of parvalbumin-positive GABAergic interneurons in DLS rescued the enhanced lever-pressing behavior and decreased MSN firing of FAE mice, it did not ameliorate habit formation 
Model 1

Associative-sensorimotor unbalance

Control $\Rightarrow$ Increased function (FAE)

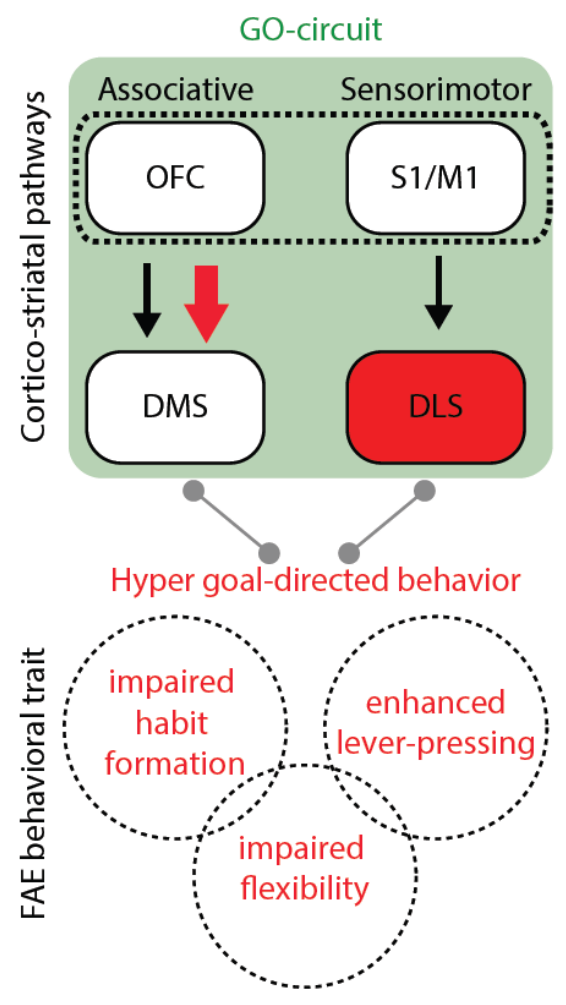

Figure 3. Model 1 of associative-sensorimotor imbalance. The associative-sensorimotor imbalance model posits that FAE promotes hyper goal-directed behavior; while the enhanced lever-pressing behavior derives from hyperfunctional sensorimotor pathway (S1/M1-DLS), the impaired habit formation and behavioral flexibility are due to a hyperactive associative pathway (OFC-DMS).

on MSNs via lateral OFC stimulation ameliorated compulsive grooming. Thus, this data further indicate that associative pathway activation prevents the expression of aberrant habitual behavior.

As described above, EtOH exposure during brain development profoundly impacts behavioral flexibility, which also relies on the intact functionality of corticostriatal associative pathway. In fact, neuronal impairments in both OFC and DMS affect reversal learning in humans, primates and rodents $(24,137,165,166)$. While hypoactivation of OFC characterizes deficits in reversal learning in animal models of OCD (167), recent data suggest that synaptic strengthening and weakening of secondary motor cortex and OFC striatal inputs, respectively, contribute to compulsive behavior in a model of OCD (168). Further, the OFC-striatal associative pathway is hyperactive during specific phases of a reversal-learning task in FAE offspring (146). This evidence supports the idea that hyperactive associative pathways would not only 
impede habit formation, but the enhanced goal-directed behavior would also interfere with the formation of novel action-outcome associations, thus resulting in cognitive flexibility impairments (Figure 3a). Chemogenetic and optogenetic experiments in FAE mice will further clarify the contribution of imbalanced function of associative and sensorimotor striatal circuits to the aberrant operant responding, habit formation and behavioral inflexibility in preclinical models of FASD.

\section{Model 2: Impaired prefrontal-striatal suppression circuits}

Suppression (or inhibition) of behavioral responses is a fundamental aspect of executive function. To obtain a desirable outcome under given circumstances, individuals need to select a defined behavioral program (23), which requires the suppression of neurobehavioral processes that might interfere or compete with the execution of that particular action. The inability to inhibit motor or cognitive programs is a hallmark of action repetition in several neuropsychiatric disorders, including OCD (169) and addiction (170). As described above, FASD symptoms share some traits with those diseases, as evidenced by the enhanced operant responding, behavioral inflexibility and addiction vulnerability following FAE (105). Although the discussion of the behavioral roles of the different prefrontal cortex (PFC) subdivisions and their projection targets goes beyond the scope of this review, it is important to recognize that the mediolateral and dorso-ventral PFC control different aspects of behavioral execution $(171,172)$. Inactivation studies indicate that the prelimbic and infralimbic PFC subregions are necessary to suppress premature and nonspecific actions in instrumental tasks or inhibit behavioral responses in go/no-go tasks (173-177). Moreover, human imaging studies reported impaired fronto-striatal network activity during behavioral inhibition tasks in both ADHD and FASD patients $(178,179)$. Inactivation studies further indicate that the PFC is necessary for appropriate reversal learning upon cross-modality changes (180-182), most likely by suppressing either obsolete action-outcome associations and/or actions dictated by previously learned sets of rules. Altogether, these studies support a second model by which an FAE-induced dysfunctional prefrontal-striatal pathway impairs behavioral suppression and results in operant responding and flexibility defects (Figure 4). Assessing resistance to punishment (or compulsivity) as a metric of perseverative and inflexible behavior would be interesting to probe the function of prefrontal-striatal networks in FAE mice. In fact, compulsive behavior seems to originate from hypofunctional prefrontal-striatal inhibitory circuits (183), which are normally recruited when an aversive stimulus (e.g. foot-shock) is paired with cocaine administration to discontinue drug-taking.

Recent data indicating that a potentiation of prefrontal-striatal inputs enhances operant responding in animal models of compulsivity challenge this second model. In fact, cocaine-withdrawal potentiates PFC-NAc inputs to drive cocaine-seeking (184) and strengthening or depressing prefrontal-striatal pathway increases and decreases alcohol-seeking (185), respectively. However, we should note that different 
subregions of the PFC (dorsal vs ventral) play different roles in compulsivity and their manipulations might either enhance or suppress drug-taking depending on the behavioral paradigm (172).

Model 2

Impaired prefrontal-striatal suppression circuit
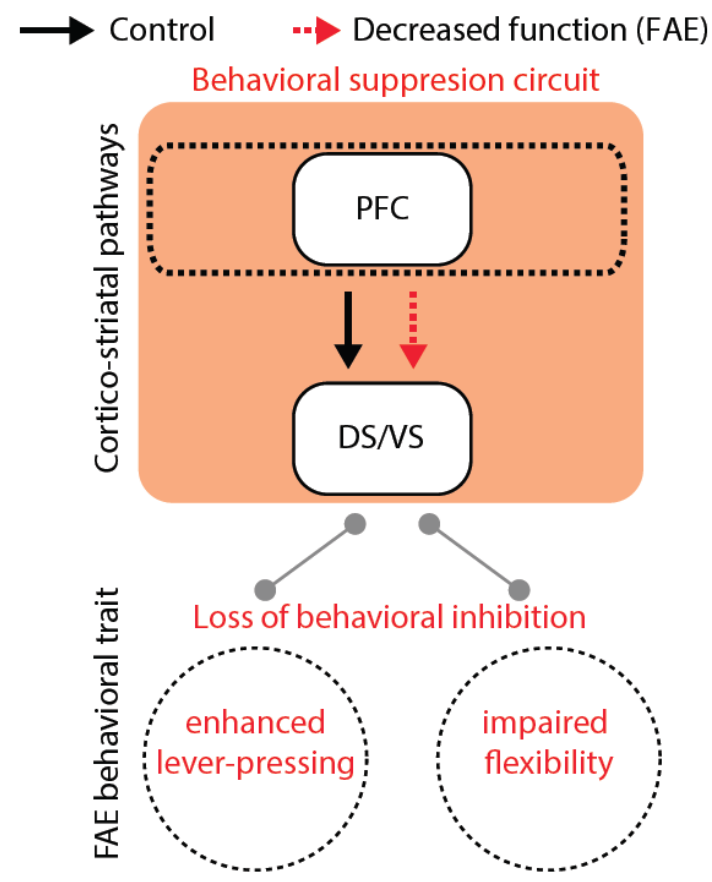

Figure 4. Model 2 of impaired prefrontal-striatal suppression circuits. The prefrontal-striatal suppression circuit model posits that a dysfunctional PFC-striatal pathway fails at suppressing behavioral responding, resulting in enhanced lever-pressing. It also implies that the inability to suppress previously learned action-outcome associations results in behavioral inflexibility when novel action-outcome associations are needed.
It should also be noted that this second model does not necessarily require functional impairments in associative or sensorimotor pathways. In fact, deficits in the PFC-striatal loop might result in the failure to suppress behavioral programs that originate from associative and sensorimotor inputs but are not normally engaged. Other than PFC, OFC-striatal pathways have also been implicated in behavioral response inhibition. For example, depotentiation of OFC-DMS inputs reduced compulsive DA neuron-self stimulation in a model of reward-seeking despite punishment (186) and self-grooming is inhibited by OFC neuron stimulation via reduced MSN activity (164). Thus, we believe that the elucidation of the defects in corticostriatal inhibitory circuits following FAE is of paramount importance to better understand the circuit defects underlying the perseverative behaviors and the impaired reversal learning following FAE. 


\section{Model 3: Striatal output pathway deficits}

A third and alternative model that could explain the behavioral deficits induced by FAE entails a disruption of striatal output pathway activity to impair executive function (Figure 5). It has been proposed

\section{Model 3}

Striatal output ensemble deficits

\section{Control}

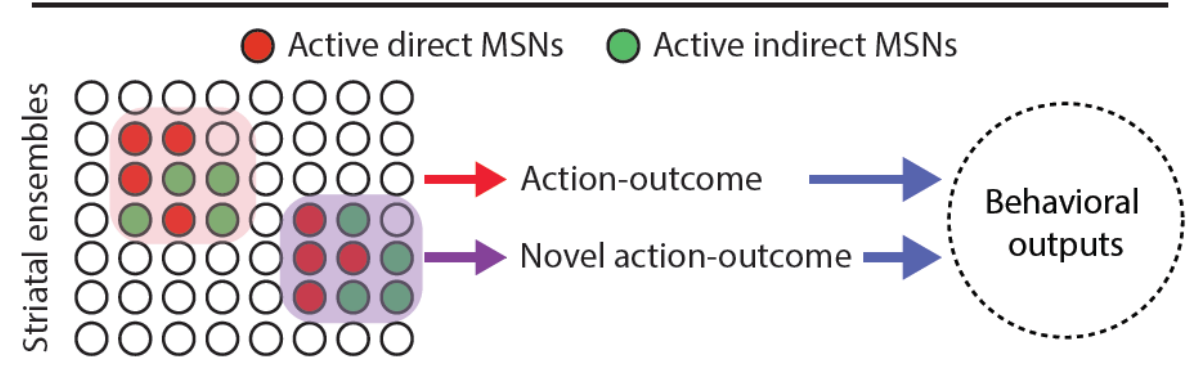

\section{FAE}

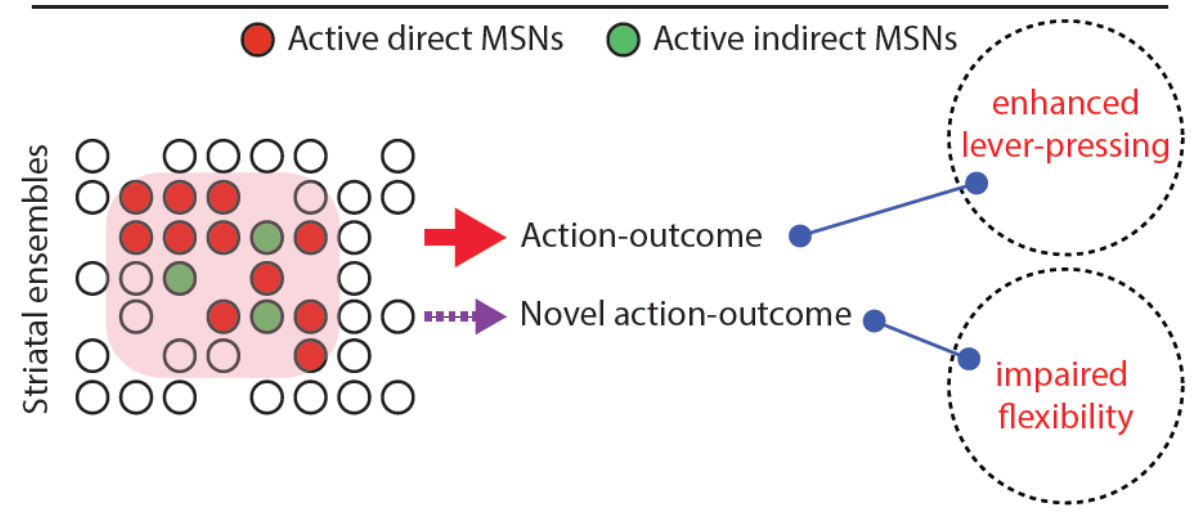

Figure 5. Model 3 of striatal output ensemble deficits. The striatal output deficit model implies that local striatal dysfunctions might induce an aberrant recruitment of striatal MSN ensembles. The heightened excitability of direct pathway MSNs would prevail upon indirect pathway inhibitory signals to strengthen action-outcome associations and increase action repetition (e.g. lever-pressing). Additionally, the increased striatal ensembles would preclude the formation of other MSN ensembles that would encode novel action-outcome associations thus resulting in behavioral inflexibility.

within a discrete striatal ensemble, determines the execution of an action (123). According to this idea, the enhanced lever pressing behavior observed during RR training of FAE mice (107) might be mediated by an exaggerated recruitment of direct MSNs within a given striatal ensemble (Figure 5). Direct MSN hyperactivity would largely prevail on the inhibitory function of indirect MSNs resulting in aberrant repetition of the same action. Moreover, the FAE-induced dysfunctions in reversal learning might reflect dysfunctional recruitment of novel striatal ensembles to update striatal output information and allow new behavioral patterns to stabilize (Figure 5). The evidence that an endocannabinoid-mediated reduction in local GABAergic tone enhances MSN excitability in DLS (107), possibly deregulating striatal neuron
(123) that discrete ensembles of striatal neurons control learning and execution of specific actions. While early studies proposed a go/no-go model whereby direct and indirect MSNs have opposing roles in behavioral execution $(187,188)$, recent in vivo studies indicate that increased activity in both striatal output pathways determines the selection of an appropriate action (189). To reconcile these apparently conflicting models, we hypothesized that the balance between go and no-go signals, respectively encoded by direct and indirect MSNs 
ensemble function, further corroborates this idea. Finally, the role of dopamine in controlling both the recruitment of MSN ensembles (190) and the synaptic plasticity at lateral inhibitory synapses between MSNs $(191,192)$ suggests that a deregulated dopamine signaling might also impair the local GABAmediated control of striatal output function following FAE.

Altogether these data strengthen the idea that FAE-induced executive function deficits originate from complex interactions between corticostriatal input, dopaminergic and GABAergic signaling impairments to recruit aberrant striatal neuron ensembles. Single-cell recordings and calcium imaging experiments in medial and/or lateral striatal subdivisions together with cortical input manipulations will help to clarify the contribution of each corticostriatal pathway to the FAE-induced behavioral symptoms. The identification of abnormal brain circuits will then allow a mechanistic approach to test the efficacy of drugs and other neuronal circuit manipulations to ameliorate the cognitive impairments induced by FAE.

\section{Preclinical interventions for FAE-induced behavioral dysfunctions}

Although the CDC describes FASD as a chronic and untreatable disorder, some medications seem to ameliorate specific neurobehavioral symptoms. In fact, despite variable outcomes $(6,193)$, psychostimulant drugs used for ADHD treatment ameliorate hyperactivity and attention deficit symptoms of FASD patients. However, while very few clinical studies have focused on finding novel therapeutic options for FASD (194), there is a large body of preclinical literature focused on preventing, ameliorating and/or rescuing cognitive deficits induced by FAE (6). Here, we review some of the pre-clinical studies that provided a neurobiological mechanism underlying the behavioral benefits following drug administration. Based on the timing of intervention, we propose a distinction between: (A) protective treatments that overlap with fetal EtOH exposure to prevent FAE symptoms; (B) restorative strategies that begin after the onset and throughout EtOH exposure and early postnatal periods, to attenuate or rescue neurobehavioral impairments; and (C) acute options, which consist in brief treatments during adolescence and adulthood, once brain maturation is complete (Figure 6). In the first category, the polyphenol flavonoid dihydromyricetin prevents the alcohol-mediated enhancement of $\mathrm{GABA}_{\mathrm{A}} \mathrm{R}$ function and protects against some of the FAE-induced behavioral dysfunctions (195), thus opening the possibility of natural supplementation use for FASD prevention. Similarly, when co-administered with EtOH at early postnatal stages, lithium prevents neurodegeneration, hippocampal LTP deficits and aberrant cortical paired-pulse facilitation (145). 


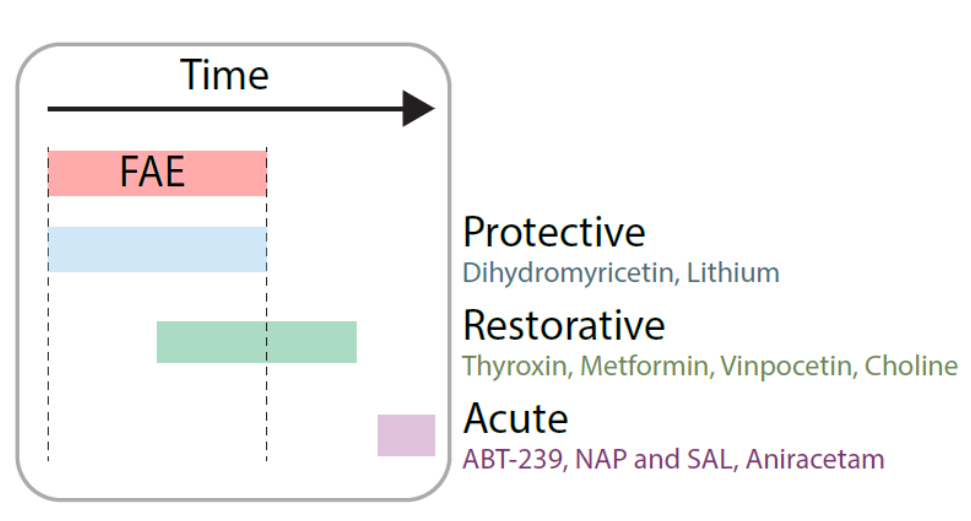

Figure 6. Potential therapeutic approaches for neurobiological and behavioral dysfunctions in pre-clinical models of FAE. Based on the timing of intervention, the therapeutic approaches can be divided into protective, which overlaps with FAE, restorative, which partially overlap but are often protracted beyond FAE and acute, which involves the administration of the treatment after the end of the FAE (typically starting during adolescence or adulthood).

and is supported by the evidence that reduced levels of thyroid hormones disrupts LTP in neonatal mice $(198,199)$. Other restorative treatments include the administration of a neural plasticity enhancer, vinpocetine (a phosphodiesterase type I inhibitor), which restores ocular dominance plasticity in a ferret model of FAE (200), or choline supplementation during early postnatal days, which promotes both spatial learning and behavioral flexibility in FAE adolescent offspring (201-203). Although the mechanisms of action of choline supplementation remain unclear, choline is a precursor of the neuromodulator acetylcholine. Among other functions, acetylcholine (ACh) controls dopamine release via activation of muscarinic and nicotinic receptors onto peduncolopontine afferents or striatal pre-synaptic dopaminergic terminals (204). Importantly, acetylcholine-mediated dopamine release is an important regulator of corticostriatal plasticity (205). Thus, an intriguing hypothesis is that choline might promote acetylcholine production, which in turn could modulate and normalize dopamine release and regulate dopaminedependent corticostriatal plasticity in FAE mice.

Acute treatments for FAE-induced deficits include the administration of the cognitive enhancer ABT-239 (a histamine receptor 3 antagonist), which ameliorates fear learning and spatial memory defects as well as altered LTP induction in the dentate gyrus of FAE offspring $(206,207)$. The neuroprotective peptides NAP (NAPVSIPQ) and SAL (SALLRSIPA), which demonstrated brain permeability upon intranasal or systemic injections (208), appear to protect against learning impairments (209) and NMDAR subunit composition deficits (210) in FAE rodents. More recently, it has been shown that a 10-day long NAP and SAL treatment during adolescence also rescues spatial learning and restores appropriate NMDAR subunit composition in the hippocampus, neocortex and cerebellum of FAE offspring (211). Aniracetam, a nootropic enhancer of AMPAR function, administered for 10 days during adolescence reduced anxiety, 
improved learning and rescued the reduced AMPAR current frequency and amplitude in a rat model of FAE (212). Altogether, these data suggest potential therapeutic use of these compounds later in life. Finally, non-pharmacological interventions, including physical activity or brain stimulation might be effective in rescuing FASD cognitive deficits. For example, it has been shown that voluntary exercise during late adolescence improves spatial memory as well as LTP deficits in the dentate gyrus of FAE offspring (213). In recent years, the improved understanding of brain circuit dysfunctions underling specific behavioral impairments led to the establishment of targeted brain stimulation protocols to ameliorate symptoms of several neuropsychiatric disorders, including Parkinson's disease (214), drug-addiction (215), depression (216). Interestingly, most of the deep-brain stimulation (DBS) or transcranial magnetic stimulation (TMS) paradigms focused on cortico-striatal circuits and appeared to be effective in rescuing neuronal circuit deficits as well as some of the neurobehavioral symptoms shared with FASD. Recently, a double-blind randomized study reported that transcranial direct current stimulation of dorso-lateral PFC improved attention upon continuous training to enhance cognitive function in FASD children (217), demonstrating both the safety and the efficacy of targeted neural stimulation in young patients. While this clinical study represents an important step in developing novel therapeutic options for FASD, pre-clinical studies will be instrumental for elucidating the effects of drugs or circuit stimulation on cortico-striatal function to provide a mechanistic understanding of the neurobiological effects of those treatments in humans.

\section{Conclusions}

The cognitive impairments associated with FASD negatively impact patient everyday life resulting in high societal and economic burden. The lack of knowledge about brain circuits related to those symptoms has slowed progress towards the development of effective therapeutic strategies. Here, we discussed three models of corticostriatal circuit dysfunctions that could account for the executive deficits observed in FASD preclinical models. A better understanding of neuronal deficits underlying those behavioral impairments will enormously benefit the development of effective therapeutic interventions for FASD patients. Different techniques enable precise circuit dissection of brain deficits in animal models of psychiatric disorders; slice physiology (ex vivo) recordings can help to clarify the role of synaptic and neuronal excitability in cortical and striatal regions, while in vivo electrophysiology can provide useful insights on the FAE-induced functional impairments of cortical or striatal neurons in behaving animals. The use of optogenetic techniques allows a powerful dissection of input-output circuit dysfunctions. Additionally, imaging calcium transients as a proxy for neuronal activity in large neuronal cellular populations can provide a better understanding of the FAE effects on the recruitment of striatal neuron ensembles. After the careful dissection of circuit dysfunctions, chemogenetic and optogenetic approaches could be applied to rescue aberrant neuronal activity in defined brain regions to ameliorate, for example, discrete executive function 
deficits. These approaches will help to tailor precise translational approaches to defined brain circuits and to understand which dysfunctional aspects of circuit physiology (e.g. loss of synaptic plasticity, enhanced excitability, imbalanced pathway function and/or altered neuronal ensemble recruitment) need to be ameliorated to obtain effective rescue strategies. These experiments would have particularly high translational value because they can be used to target other FASD traits, such as socio-emotional dysfunctions, and/or similar neurobehavioral symptoms of other neuropsychiatric disorders.

\section{REFERENCES}

1. May PA, Gossage JP, Kalberg WO, Robinson LK, Buckley D, Manning M, Hoyme HE (2009): Prevalence and epidemiologic characteristics of FASD from various research methods with an emphasis on recent in-school studies. Dev Disabil Res Rev 15: 176-192.

2. May PA, Baete A, Russo J, Elliott AJ, Blankenship J, Kalberg WO, et al. (2014): Prevalence and Characteristics of Fetal Alcohol Spectrum Disorders. Pediatrics 134: 855-866.

3. Riley EP, Infante MA, Warren KR (2011, June): Fetal alcohol spectrum disorders: An overview. Neuropsychology Review, vol. 21. pp 73-80.

4. Stade B, Ungar WJ, Stevens B, Beyen J, Koren G (2007): Cost of fetal alcohol spectrum disorder in Canada. Can Fam Physician 53: 1303-1304.

5. Chasnoff IJ, Wells AM, King L (2015): Misdiagnosis and missed diagnoses in foster and adopted children with prenatal alcohol exposure. Pediatrics 135: 264-270.

6. Murawski NJ, Moore EM, Thomas JD, Riley EP (2015): Advances in diagnosis and treatment of fetal alcohol spectrum disorders: From animal models to human studies. Alcohol Res Curr Rev 37: 97108.

7. Chokroborty-Hoque A, Alberry B, Singh SM (2014): Exploring the complexity of intellectual disability in fetal alcohol spectrum disorders. Front Pediatr 2: 1-9.

8. Streissguth A (2007): Offspring effects of prenatal alcohol exposure from birth to 25 years: The Seattle prospective longitudinal study. J Clin Psychol Med Settings 14: 81-101.

9. Spohr HL, Steinhausen HC (1984): Clinical, psychopathological and developmental aspects in children with the fetal alcohol syndrome: a four-year follow-up study. Ciba Found Symp 105: 197-217.

10. Connor PD, Sampson PD, Bookstein FL, Barr HM, Streissguth AP (2000): Direct and indirect effects of prenatal alcohol damage on executive function. Dev Neuropsychol 18: 331-354.

11. Rangmar J, Sandberg AD, Aronson M, Fahlke C (2015): Cognitive and executive functions, social cognition and sense of coherence in adults with fetal alcohol syndrome. Nord J Psychiatry 69: 472478.

12. Autti-Rämö I (2000): Twelve-year follow-up of children exposed to alcohol in utero. Dev Med Child Neurol 42: 406-411.

13. Baer JS, Sampson PD, Barr HM, Connor PD, Streissguth AP (2003): A 21 -year longitudinal analysis of the effects of prenatal alcohol exposure on young adult drinking. Arch Gen Psychiatry 60: 377385.

14. Streissguth AP, Aase JM, Clarren SK, Randels SP, Ladue RA, Smith DF (1991): Fetal Alcohol 
Syndrome in Adolescents and Adults. JAMA J Am Med Assoc 265: 1961-1967.

15. STEINHAUSEN HC, WILLMS J, SPOHR HL (1993): Long-Term Psychopathological and Cognitive Outcome of Children with Fetal Alcohol Syndrome. J Am Acad Child Adolesc Psychiatry 32: 990994.

16. Kerns KA, Don A, Mateer CA, Streissguth AP (1997): Cognitive Deficits in Nonretarded Adults with Fetal Alcohol Syndrome. J Learn Disabil 30: 685-693.

17. Jones KL, Smith DW (1973): Recognition of the Fetal Alcohol Syndrome in Early Infancy. Lancet 302: 999-1001.

18. Streissguth AP, Clarren SK, Jones KL (1985): Natural History of the Fetal Alcohol Syndrome: a 10Year Follow-Up of Eleven Patients. Lancet 326: 85-91.

19. Coles CD, Brown RT, Smith IE, Platzman KA, Erickson S, Falek A (1991): Effects of prenatal alcohol exposure at school age. I. Physical and cognitive development. Neurotoxicol Teratol 13: $357-367$.

20. Brown RT, Coles CD, Smith IE, Platzman KA, Silverstein J, Erickson S, Falek A (1991): Effects of prenatal alcohol exposure at school age. II. Attention and behavior. Neurotoxicol Teratol 13: 369376.

21. Thomas SE, Kelly SJ, Mattson SN, Riley EP (1998): Comparison of social abilities of children with fetal alcohol syndrome to those of children with similar IQ scores and normal controls. Alcohol Clin Exp Res 22: 528-533.

22. Kelly SJ, Day N, Streissguth AP (2000): Effects of prenatal alcohol exposure on social behavior in humans and other species. Neurotoxicol Teratol 22: 143-149.

23. Diamond A (2013): Executive functions. Annu Rev Psychol 64: 135-168.

24. Izquierdo A, Brigman JL, Radke AK, Rudebeck PH, Holmes A (2017): The neural basis of reversal learning: An updated perspective. Neuroscience 345: 12-26.

25. Green CR, Mihic AM, Nikkel SM, Stade BC, Rasmussen C, Munoz DP, Reynolds JN (2009): Executive function deficits in children with fetal alcohol spectrum disorders (FASD) measured using the Cambridge Neuropsychological Tests Automated Battery (CANTAB). J Child Psychol Psychiatry Allied Discip 50: 688-697.

26. Kodituwakku PW, Handmaker NS, Cutler SK, Weathersby EK, Handmaker SD (1995): Specific Impairments in Self-Regulation in Children Exposed to Alcohol Prenatally. Alcohol Clin Exp Res 19: $1558-1564$.

27. Mattson SN, Goodman AM, Caine C, Delis DC, Riley EP (1999): Executive functioning in children with heavy prenatal alcohol exposure. Alcohol Clin Exp Res 23: 1808-1815.

28. Mattson SN, Bernes GA, Doyle LR (2019): Fetal Alcohol Spectrum Disorders: A Review of the Neurobehavioral Deficits Associated With Prenatal Alcohol Exposure. Alcohol Clin Exp Res 43: 1046-1062.

29. Schonfeld AM, Mattson SN, Lang AR, Delis DC, Riley EP (2001): Verbal and nonverbal fluency in children with heavy prenatal alcohol exposure. J Stud Alcohol 62: 239-246.

30. Roebuck TM, Mattson SN, Riley EP (1999): Behavioral and psychosocial profiles of alcohol-exposed children. Alcohol Clin Exp Res 23: 1070-1076. 
31. Coles CD, Platzman KA, Raskind-Hood CL, Brown RT, Falek A, Smith IE (1997): A comparison of children affected by prenatal alcohol exposure and attention deficit, hyperactivity disorder. Alcohol Clin Exp Res 21: 150-161.

32. Mattson SN, Riley EP, Delis DC, Stern C, Jones KL (1996): Verbal learning and memory in children with fetal alcohol syndrome. Alcohol Clin Exp Res 20: 810-816.

33. Mattson SN, Riley EP, Gramling L, Delis DC, Jones KL (1998): Neuropsychological comparison of alcohol-exposed children with or without physical features of fetal alcohol syndrome. Neuropsychology 12: 146-153.

34. Olson HC, Feldman JJ, Streissguth AP, Sampson PD, Bookstein FL (1998): Neuropsychological deficits in adolescents with fetal alcohol syndrome: Clinical findings. Alcohol Clin Exp Res 22: 1998-2012.

35. Patten AR, Fontaine CJ, Christie BR (2014): A Comparison of the Different Animal Models of Fetal Alcohol Spectrum Disorders and Their Use in Studying Complex Behaviors. Front Pediatr 2. https://doi.org/10.3389/fped.2014.00093

36. Sadrian B, Wilson DA, Saito M (2013): Long-lasting neural circuit dysfunction following developmental ethanol exposure. Brain Sci 3: 704-727.

37. Rasmussen C, Andrew G, Zwaigenbaum L, Tough S (2008): Neurobehavioural outcomes of children with fetal alcohol spectrum disorders: A Canadian perspective. Paediatr Child Health (Oxford) 13: $185-191$.

38. Fryer SL, McGee CL, Matt GE, Riley EP, Mattson SN (2007): Evaluation of psychopathological conditions in children with heavy prenatal alcohol exposure. Pediatrics 119. https://doi.org/10.1542/peds.2006-1606

39. Burd L (2016): FASD and ADHD: Are they related and How? BMC Psychiatry 16: 9-11.

40. Rojas-Mayorquín AE, Padilla-Velarde E, Ortuño-Sahagún D (2016): Prenatal alcohol exposure in rodents as a promising model for the study of ADHD molecular basis. Front Neurosci 10: 1-10.

41. Bishop S, Gahagan S, Lord C (2007): Re-examining the core features of autism: A comparison of autism spectrum disorder and fetal alcohol spectrum disorder. J Child Psychol Psychiatry Allied Discip 48: 1111-1121.

42. Famy C, Streissguth AP, Unis AS (1998): Mental illness in adults with fetal alcohol syndrome or fetal alcohol effects. Am J Psychiatry 155: 552-554.

43. Marquardt K, Brigman JL (2016): The impact of prenatal alcohol exposure on social, cognitive and affective behavioral domains: Insights from rodent models. Alcohol 51: 1-15.

44. Muggli E, O’Leary C, Donath S, Orsini F, Forster D, Anderson PJ, et al. (2016): Did you ever drink more? A detailed description of pregnant women's drinking patterns. BMC Public Health 16. https://doi.org/10.1186/s12889-016-3354-9

45. May PA, Gossage JP (2011): Maternal risk factors for fetal alcohol spectrum disorders: Not as simple as it might seem. Alcohol Res Heal 34: 15-26.

46. Ashwell KWS, Mai JK (2012): Fetal Development of the Central Nervous System. The Human Nervous System. https://doi.org/10.1016/B978-0-12-374236-0.10003-3

47. Burd L, Blair J, Dropps K (2012): Prenatal alcohol exposure, blood alcohol concentrations and alcohol elimination rates for the mother, fetus and newborn. $J$ Perinatol 32: 652-659. 
48. Bakhireva LN, Savage DD (2011): Focus on: biomarkers of fetal alcohol exposure and fetal alcohol effects. Alcohol Res Health 34: 56-63.

49. Abernethy C, McCall KE, Cooper G, Favretto D, Vaiano F, Bertol E, Mactier H (2018): Determining the pattern and prevalence of alcohol consumption in pregnancy by measuring biomarkers in meconium. Arch Dis Child Fetal Neonatal Ed 103: F216-F220.

50. Guerri C, Bazinet A, Riley EP (2009): Foetal alcohol spectrum disorders and alterations in brain and behaviour. Alcohol Alcohol 44: 108-114.

51. C. C, R.C. M (2007): Ethanol exposure during neurogenesis induces persistent effects on neural maturation: Evidence from an ex vivo model of fetal cerebral cortical neuroepithelial progenitor maturation. Gene Expr 14: 159-171.

52. Chang GQ, Karatayev O, Liang SC, Barson JR, Leibowitz SF (2012): Prenatal ethanol exposure stimulates neurogenesis in hypothalamic and limbic peptide systems: Possible mechanism for offspring ethanol overconsumption. Neuroscience. https://doi.org/10.1016/j.neuroscience.2012.05.066

53. Aronne MP, Guadagnoli T, Fontanet P, Evrard SG, Brusco A (2011): Effects of prenatal ethanol exposure on rat brain radial glia and neuroblast migration. Exp Neurol. https://doi.org/10.1016/j.expneurol.2011.03.002

54. SUSAN E. MAIER, PH.D., AND JAMES R. WEST PD, The (2001): Drinking Patterns and AlcoholRelated Birth Defects. Alcohol Res Heal 25(3):168-.

55. Olsen J (1994): Effects of Moderate Alcohol Consumption During Pregnancy on Child Development at 18 and 42 Months. Alcohol Clin Exp Res 18: 1109-1113.

56. Ornoy A, Ergaz Z (2010): Alcohol abuse in pregnant women: Effects on the fetus and newborn, mode of action and maternal treatment. Int J Environ Res Public Health 7: 364-379.

57. Clancy B (2016): Translating time across mammalian species. 4522: 6-17.

58. Kasanetz F, Manzoni OJ (2009): Maturation of excitatory synaptic transmission of the rat nucleus accumbens from juvenile to adult. J Neurophysiol 101: 2516-2527.

59. Peixoto RT, Wang W, Croney DM, Kozorovitskiy Y, Sabatini BL (2016): Early hyperactivity and precocious maturation of corticostriatal circuits in Shank3B â '/â' mice. Nat Neurosci 19: 716-724.

60. Allan AM, Chynoweth J, Tyler LA, Caldwell KK (2003): A Mouse Model of Prenatal Ethanol Exposure Using a Voluntary Drinking Paradigm. Alcohol Clin Exp Res 27: 2009-2016.

61. Lieber CS, Decarli LM, Sorrell MF (1989): Experimental methods of ethanol administration. Hepatology 10: 501-510.

62. Diaz-Granados JL, Graham DL (2007): The effects of continuous and intermittent ethanol exposure in adolesence on the aversive properties of ethanol during adulthood. Alcohol Clin Exp Res 31: 20202027.

63. Webster WS, Walsh DA, McEwen SE, Lipson AH (1983): Some teratogenic properties of ethanol and acetaldehyde in C57BL/6J mice: Implications for the study of the fetal alcohol syndrome. Teratology 27: 231-243.

64. DeCarli LM, Lieber CS (1967): Fatty Liver in the Rat after Prolonged Intake of Ethanol with a Nutritionally Adequate New Liquid Diet. J Nutr 91: 331-336. 
65. Bake S, Tingling JD, Miranda RC (2012): Ethanol Exposure During Pregnancy Persistently Attenuates Cranially Directed Blood Flow in the Developing Fetus: Evidence from Ultrasound Imaging in a Murine Second Trimester Equivalent Model. Alcohol Clin Exp Res 36: 748-758.

66. Kelly SJ, Lawrence CR (2008): Intragastric intubation of alcohol during the perinatal period. Methods Mol Biol 447: 101-110.

67. Goldstein DB, Pal N (1970): Alcohol dependence produced in mice by inhalation of ethanol: grading the withdrawal reaction. Science (80-) 172: 288-290.

68. Becker HC, Lopez MF (2004): Increased ethanol drinking after repeated chronic ethanol exposure and withdrawal experience in C57BL/6 mice. Alcohol Clin Exp Res 28: 1829-1838.

69. Griffin WC, Lopez MF, Becker HC (2009): Intensity and duration of chronic ethanol exposure is critical for subsequent escalation of voluntary ethanol drinking in mice. Alcohol Clin Exp Res 33: 1893-1900.

70. Nuñez SC, Roussotte F, Sowell ER (2011): Focus on: Structural and functional brain abnormalities in fetal alcohol spectrum disorders. Alcohol Res Heal 34: 121-132.

71. Archibaldma SL, Fennema-Notestine C, Gamst A, Riley EP, Mattson SN, Jernigan TL (2001): Brain dysmorphology in individuals with severe prenatal alcohol exposure. Dev Med Child Neurol 43: $148-154$.

72. Spadoni AD, McGee CL, Fryer SL, Riley EP (2007): Neuroimaging and fetal alcohol spectrum disorders. Neurosci Biobehav Rev 31: 239-245.

73. Swartzwelder HS, Farr KL, Wilson WA, Savage DD (1988): Prenatal exposure to ethanol decreases physiological plasticity in the hippocampus of the adult rat. Alcohol 5: 121-124.

74. Chepkova AN, Doreulee N, Trofimov SS, Gudasheva TA, Ostrovskaya RU, Skrebitsky VG, ABrain (1995): Nootropic compound L-pyroglutamyl-D-alanine-amide restores hippocampal long-term potentiation impaired by exposure to ethanol in rats. Neurosci Lett 188: 163-166.

75. Bellinger FP, Bedi KS, Wilson P, Wilce PA (1999): Ethanol exposure during the third trimester equivalent results in long- lasting decreased synaptic efficacy but not plasticity in the CA1 region of the rat hippocampus. Synapse 31: 51-58.

76. Tan SE, Berman RF, Abel EL, Zajac CS (1990): Prenatal alcohol exposure alters hippocampal slice electrophysiology. Alcohol 7: 507-511.

77. Izumi Y, Kitabayashi R, Funatsu M, Izumi M, Yuede C, Hartman RE, et al. (2005): A single day of ethanol exposure during development has persistent effects on bi-directional plasticity, N-methyl-Daspartate receptor function and ethanol sensitivity. Neuroscience 136: 269-279.

78. Patten AR, Gil-Mohapel J, Wortman RC, Noonan A, Brocardo PS, Christie BR (2013): Effects of ethanol exposure during distinct periods of brain development on hippocampal synaptic plasticity. Brain Sci 3: 1076-1094.

79. Sutherland RJ, McDonald RJ, Savage DD (2000): Prenatal exposure to moderate levels of ethanol can have long-lasting effects on learning and memory in adult offspring. Psychobiology 28: 532-539.

80. Sickmann HM, Patten AR, Morch K, Sawchuk S, Zhang C, Parton R, et al. (2014): Prenatal ethanol exposure has sex-specific effects on hippocampal long-term potentiation. Hippocampus 24: 54-64.

81. Savage DD, Cruz LL, Duran LM, Paxton LL (1998): Prenatal ethanol exposure diminishes activitydependent potentiation of amino acid neurotransmitter release in adult rat offspring. Alcohol Clin 
Exp Res 22: 1771-1777.

82. Lunde-Young R, Ramirez J, Naik V, Orzabal M, Lee J, Konganti K, et al. (2019): Hippocampal transcriptome reveals novel targets of FASD pathogenesis. Brain Behav e01334.

83. Fontaine CJ, Pinar C, Yang W, Pang AF, Suesser KE, Choi JSJ, Christie BR (2019): Impaired bidirectional synaptic plasticity in juvenile offspring following prenatal ethanol exposure. Alcohol Clin Exp Res acer.14170.

84. O'Connell LA, Hofmann HA (2011): The Vertebrate mesolimbic reward system and social behavior network: A comparative synthesis. J Comp Neurol 519: 3599-3639.

85. Bellone C, Mameli M, Lüscher C (2011): In utero exposure to cocaine delays postnatal synaptic maturation of glutamatergic transmission in the VTA. Nat Neurosci 14: 1439-1446.

86. Bariselli S, Tzanoulinou S, Glangetas C, Prévost-Solié C, Pucci L, Viguié J, et al. (2016): SHANK3 controls maturation of social reward circuits in the VTA. Nat Neurosci 19. https://doi.org/10.1038/nn.4319

87. Hausknecht K, Haj-Dahmane S, Shen YL, Vezina P, Dlugos C, Shen RY (2015): Excitatory synaptic function and plasticity is persistently altered in ventral tegmental area dopamine neurons after prenatal ethanol exposure. Neuropsychopharmacology 40: 893-905.

88. Mameli M, Bellone C, Brown MTC, Lüscher C (2011): Cocaine inverts rules for synaptic plasticity of glutamate transmission in the ventral tegmental area. Nat Neurosci 14: 414-416.

89. Hausknecht K, Shen YL, Wang RX, Haj-Dahmane S, Shen RY (2017): Prenatal ethanol exposure persistently alters endocannabinoid signaling and endocannabinoid-mediated excitatory synaptic plasticity in ventral tegmental area dopamine neurons. J Neurosci 37: 5798-5808.

90. Wang J, Haj-Dahmane S, Shen RY (2006): Effects of prenatal ethanol exposure on the excitability of ventral tegmental area dopamine neurons in vitro. J Pharmacol Exp Ther 319: 857-863.

91. Zhou R, Wang S, Zhu X (2010): Prenatal ethanol exposure attenuates GABAergic inhibition in basolateral amygdala leading to neuronal hyperexcitability and anxiety-like behavior of adult rat offspring. Neuroscience 170: 749-757.

92. Servais L, Hourez R, Bearzatto B, Gall D, Schiffmann SN, Cheron G (2007): Purkinje cell dysfunction and alteration of long-term synaptic plasticity in fetal alcohol syndrome. Proc Natl Acad Sci US A 104: 9858-9863.

93. Mohammad S, Page SJ, Wang L, Ishii S, Li P, Sasaki T, et al. (2020): Kcnn2 blockade reverses learning deficits in a mouse model of fetal alcohol spectrum disorders. Nat Neurosci 23. https://doi.org/10.1038/s41593-020-0592-z

94. Driscoll CD, Streissguth AP, Riley EP (1990): Prenatal alcohol exposure: Comparability of effects in humans and animal models. Neurotoxicol Teratol 12: 231-237.

95. Hausknecht KA, Acheson A, Farrar AM, Kieres AK, Shen RY, Richards JB, Sabol KE (2005): Prenatal alcohol exposure causes attention deficits in male rats. Behav Neurosci 119: 302-310.

96. Louth EL, Bignell W, Taylor CL, Bailey CDC (2016): Developmental Ethanol Exposure Leads to Long-Term Deficits in Attention and Its Underlying Prefrontal Circuitry. eNeuro 3. https://doi.org/10.1523/eneuro.0267-16.2016

97. Girard TA, Xing HC, Ward GR, Wainwright PE (2000): Early postnatal ethanol exposure has longterm effects on the performance of male rats in a delayed matching-to-place task in the Morris water 
maze. Alcohol Clin Exp Res 24: 300-306.

98. March SM, Abate P, Spear NE, Molina JC (2009): Fetal exposure to moderate ethanol doses: Heightened operant responsiveness elicited by ethanol-related reinforcers. Alcohol Clin Exp Res 33: 1981-1993.

99. Miranda-Morales RS, Nizhnikov ME, Spear NE (2014): Prenatal exposure to ethanol during late gestation facilitates operant self-administration of the drug in 5-day-old rats. Alcohol 48: 19-23.

100. Culleré ME, Spear NE, Molina JC (2014): Prenatal ethanol increases sucrose reinforcement, an effect strengthened by postnatal association of ethanol and sucrose. Alcohol 48: 25-33.

101. Miranda-Morales RS, Molina JC, Spear NE, Abate P (2012): Naloxone attenuation of ethanolreinforced operant responding in infant rats in a re-exposure paradigm. Psychopharmacology (Berl) 219: $235-246$.

102. Allan AM, Goggin SL, Caldwell KK (2014): Prenatal alcohol exposure modifies glucocorticoid receptor subcellular distribution in the medial prefrontal cortex and impairs frontal cortex-dependent learning. PLoS One 9. https://doi.org/10.1371/journal.pone.0096200

103. Hamilton DA, Barto D, Rodriguez CI, Magcalas CM, Fink BC, Rice JP, et al. (2014): Effects of moderate prenatal ethanol exposure and age on social behavior, spatial response perseveration errors and motor behavior. Behav Brain Res 269: 44-54.

104. Wainwright PE, Ward GR, Winfield D, Huang Y -S, Mills DE, Ward RP, McCutcheon D (1990): Effects of Prenatal Ethanol and Long-Chain n-3 Fatty Acid Supplementation on Development in Mice. 1. Body and Brain Growth, Sensorimotor Development, and Water T-Maze Reversal Learning. Alcohol Clin Exp Res 14: 405-412.

105. Popova S, Lange S, Shield K, Mihic A, Chudley AE, Mukherjee RAS, et al. (2016): Comorbidity of fetal alcohol spectrum disorder: A systematic review and meta-analysis. Lancet 387: 978-987.

106. Gremel CM, Costa RM (2013): Orbitofrontal and striatal circuits dynamically encode the shift between goal-directed and habitual actions. Nat Commun 4: 1-12.

107. Cuzon Carlson VC, Gremel CM, Lovinger DM (2020): Gestational alcohol exposure disrupts cognitive function and striatal circuits in adult offspring. Nat Commun 11. https://doi.org/10.1038/s41467-020-16385-4

108. Olguin SL, Zimmerman A, Zhang H, Allan A, Caldwell KC, Brigman JL (2019): Increased Maternal Care Rescues Altered Reinstatement Responding Following Moderate Prenatal Alcohol Exposure. Alcohol Clin Exp Res acer.14149.

109. Marquardt K, Sigdel R, Caldwell K, Brigman JL (2014): Prenatal ethanol exposure impairs executive function in mice into adulthood. Alcohol Clin Exp Res 38: 2962-2968.

110. O'Leary-Moore SK, McMechan AP, Mathison SN, Berman RF, Hannigan JH (2006): Reversal learning after prenatal or early postnatal alcohol exposure in juvenile and adult rats. Alcohol 38: 99110.

111. Mihalick SM, Crandall JE, Langlois JC, Krienke JD, Dube W V. (2001): Prenatal ethanol exposure, generalized learning impairment, and medial prefrontal cortical deficits in rats. Neurotoxicol Teratol 23: 453-462.

112. Riley EP, Lochry EA, Shapiro NR (1979): Lack of response inhibition in rats prenatally exposed to alcohol. Psychopharmacology (Berl) 62: 47-52. 
113. Barron S, Riley EP (1990): Passive avoidance performance following neonatal alcohol exposure. Neurotoxicol Teratol 12: 135-138.

114. Riley EP, Shapiro NR, Lochry EA (1979): Nose-poking and head-dipping behaviors in rats prenatally exposed to alcohol. Pharmacol Biochem Behav 11: 513-519.

115. Jahanshahi M, Obeso I, Rothwell JC, Obeso JA (2015): A fronto-striato-subthalamic-pallidal network for goal-directed and habitual inhibition. Nat Rev Neurosci 16: 719-732.

116. Haber SN (2016): Corticostriatal circuitry. Neurosci 21st Century From Basic to Clin Second Ed $1721-1741$.

117. Wall NR, DeLaParra M, Callaway EM, Kreitzer AC (2013): Differential innervation of direct- and indirect-pathway striatal projection neurons. Neuron. https://doi.org/10.1016/j.neuron.2013.05.014

118. Gerfen CR, Engber TM, Mahan LC, Susel Z, Chase TN, Monsma Jr. FJ, Sibley DR (1994): D1 and D2 dopamine receptor-regulated gene expression of striatonigral and striatopallidal neurons. Glutamate and Parkinson's disease. AnnNeurol 35: 639-645.

119. Nicola SM, Surmeier DJ, Malenka RC (2000): D OPAMINERGIC M ODULATION OF N EURONAL E XCITABILITY IN THE. pp 185-215.

120. Kozorovitskiy Y, Peixoto R, Wang W, Saunders A, Sabatini BL (2015): Neuromodulation of excitatory synaptogenesis in striatal development. Elife 4: 1-18.

121. Shen W, Flajolet M, Greengard P, Surmeier DJ (2008): Dichotomous dopaminergic control of striatal synaptic plasticity. Science (80-) 321: 848-851.

122. Kravitz A V., Freeze BS, Parker PRL, Kay K, Thwin MT, Deisseroth K, Kreitzer AC (2010): Regulation of parkinsonian motor behaviours by optogenetic control of basal ganglia circuitry. Nature 466: 622-626.

123. Bariselli S, Fobbs WC, Creed MC, Kravitz A V (2019): A competitive model for striatal action selection. Brain Res. https://doi.org/10.1016/j.brainres.2018.10.009

124. Graybiel AM, Grafton ST (2015): The striatum: Where skills and habits meet. Cold Spring Harb Perspect Biol 7: 1-14.

125. Gremel CM, Lovinger DM (2017): Associative and sensorimotor cortico-basal ganglia circuit roles in effects of abused drugs. Genes, Brain Behav 16: 71-85.

126. Rossi MA, Yin HH (2011): The role of the dorsal striatum in instrumental conditioning. Neuromethods 62: 55-69.

127. Kupferschmidt DA, Juczewski K, Cui G, Johnson KA, Lovinger DM (2017): Parallel, but Dissociable, Processing in Discrete Corticostriatal Inputs Encodes Skill Learning. Neuron 96: 476489.e5.

128. Rudebeck PH, Saunders RC, Lundgren DA, Murray EA (2017): Specialized Representations of Value in the Orbital and Ventrolateral Prefrontal Cortex: Desirability versus Availability of Outcomes. Neuron 95: 1208-1220.e5.

129. Amodeo LR, McMurray MS, Roitman JD (2017): Orbitofrontal cortex reflects changes in responseoutcome contingencies during probabilistic reversal learning. Neuroscience 345: 27-37.

130. Yang Y, Roussotte F, Kan E, Sulik KK, Mattson SN, Riley EP, et al. (2012): Abnormal cortical thickness alterations in fetal alcohol spectrum disorders and their relationships with facial 
dysmorphology. Cereb Cortex 22: 1170-1179.

131. Zhou D, Lebel C, Lepage C, Rasmussen C, Evans A, Wyper K, et al. (2011): Developmental cortical thinning in fetal alcohol spectrum disorders. Neuroimage 58: 16-25.

132. Long X, Little G, Beaulieu C, Lebel C (2018): Sensorimotor network alterations in children and youth with prenatal alcohol exposure. Hum Brain Mapp 39: 2258-2268.

133. Abbott CW, Kozanian OO, Kanaan J, Wendel KM, Huffman KJ (2016): The Impact of Prenatal Ethanol Exposure on Neuroanatomical and Behavioral Development in Mice. Alcohol Clin Exp Res 40: $122-133$.

134. Valenzuela CF, Morton RA, Diaz MR, Topper L (2012): Does moderate drinking harm the fetal brain? Insights from animal models. Trends Neurosci 35: 284-292.

135. Delatour LC, Yeh PWL, Yeh HH (2020): Prenatal Exposure to Ethanol Alters Synaptic Activity in Layer V/VI Pyramidal Neurons of the Somatosensory Cortex. Cereb Cortex 30: 1735-1751.

136. Xie N, Yang Q, Chappell TD, Li CX, Waters RS (2010): Prenatal alcohol exposure reduces the size of the forelimb representation in motor cortex in rat: an intracortical microstimulation (ICMS) mapping study. Alcohol 44: 185-194.

137. Ragozzino ME (2007): The contribution of the medial prefrontal cortex, orbitofrontal cortex, and dorsomedial striatum to behavioral flexibility. Ann N Y Acad Sci 1121: 355-375.

138. Lawrence RC, Otero NKH, Kelly SJ (2012): Selective effects of perinatal ethanol exposure in medial prefrontal cortex and nucleus accumbens. Neurotoxicol Teratol 34: 128-135.

139. Cuzon VC, Yeh PWL, Yanagawa Y, Obata K, Yeh HH (2008): Ethanol consumption during early pregnancy alters the disposition of tangentially migrating GABAergic interneurons in the fetal cortex. J Neurosci 28: 1854-1864.

140. Skorput AGJ, Gupta VP, Yeh PWL, Yeh HH (2015): Persistent Interneuronopathy in the Prefrontal Cortex of Young Adult Offspring Exposed to Ethanol In Utero. J Neurosci 35: 10977-10988.

141. Hamilton GF, Hernandez IJ, Krebs CP, Bucko PJ, Rhodes JS (2017): Neonatal alcohol exposure reduces number of parvalbumin-positive interneurons in the medial prefrontal cortex and impairs passive avoidance acquisition in mice deficits not rescued from exercise. Neuroscience 352: 52-63.

142. Smiley JF, Saito M, Bleiwas C, Masiello K, Ardekani B, Guilfoyle DN, et al. (2015): Selective reduction of cerebral cortex GABA neurons in a late gestation model of fetal alcohol spectrum disorder. Alcohol 49: 571-580.

143. Rubenstein JLR, Merzenich MM (2003): Model of autism: increased ratio of excitation/ inhibition in key neural systems. Genes Brain Behav 2: 255-267.

144. Wilson DA, Peterson J, Basavaraj BS, Saito M (2011): Local and regional network function in behaviorally relevant cortical circuits of adult mice following postnatal alcohol exposure. Alcohol Clin Exp Res 35: 1974-1984.

145. Sadrian B, Subbanna S, Wilson DA, Basavarajappa BS, Saito M (2012): Lithium prevents long-term neural and behavioral pathology induced by early alcohol exposure. Neuroscience 206: 122-135.

146. Marquardt K, Cavanagh JF, Brigman JL (2020): Alcohol exposure in utero disrupts cortico-striatal coordination required for behavioral flexibility. Neuropharmacology 162: 107832.

147. Kenton JA, Ontiveros T, Bird CW, Valenzuela CF, Brigman JL (2020): Moderate prenatal alcohol 
exposure alters the number and function of GABAergic interneurons in the murine orbitofrontal cortex. Alcohol. https://doi.org/10.1016/j.alcohol.2020.06.001

148. Kuo HY, Liu FC (2019): Synaptic wiring of corticostriatal circuits in basal ganglia: Insights into the pathogenesis of neuropsychiatric disorders. eNeuro 6. https://doi.org/10.1523/ENEURO.007619.2019

149. Cortese BM, Moore GJ, Bailey BA, Jacobson SW, Delaney-Black V, Hannigan JH (2006): Magnetic resonance and spectroscopic imaging in prenatal alcohol-exposed children: Preliminary findings in the caudate nucleus. Neurotoxicol Teratol 28: 597-606.

150. Young C, Olney JW (2006): Neuroapoptosis in the infant mouse brain triggered by a transient small increase in blood alcohol concentration. Neurobiol Dis 22: 548-554.

151. de Giorgio A, Comparini SE, Intra FS, Granato A (2012): Long-term alterations of striatal parvalbumin interneurons in a rat model of early exposure to alcohol. J Neurodev Disord 4: 1-7.

152. Rice JP, Suggs LE, Lusk A V., Parker MO, Candelaria-Cook FT, Akers KG, et al. (2012): Effects of exposure to moderate levels of ethanol during prenatal brain development on dendritic length, branching, and spine density in the nucleus accumbens and dorsal striatum of adult rats. Alcohol 46: $577-584$.

153. Charles Lawrence R, Cale Bonner H, Newsom RJ, Kelly SJ (2008): Effects of alcohol exposure during development on play behavior and c-Fos expression in response to play behavior. Behav Brain Res 188: 209-218.

154. Cheng Y, Wang X, Wei X, Xie X, Melo S, Miranda RC, Wang J (2018): Prenatal Exposure to Alcohol Induces Functional and Structural Plasticity in Dopamine D1 Receptor-Expressing Neurons of the Dorsomedial Striatum. Alcohol Clin Exp Res 42: 1493-1502.

155. Zhou R, Wang S, Zhu X (2012): Prenatal ethanol exposure alters synaptic plasticity in the dorsolateral striatum of rat offspring via changing the reactivity of dopamine receptor. PLoS One 7. https://doi.org/10.1371/journal.pone.0042443

156. Schneider ML, Moore CF, Barnhart TE, Larson JA, DeJesus OT, Mukherjee J, et al. (2005): Moderate-level prenatal alcohol exposure alters striatal dopamine system function in rhesus monkeys. Alcohol Clin Exp Res 29: 1685-1697.

157. Barbier E, Pierrefiche O, Vaudry D, Vaudry H, Daoust M, Naassila M (2008): Long-term alterations in vulnerability to addiction to drugs of abuse and in brain gene expression after early life ethanol exposure. Neuropharmacology 55: 1199-1211.

158. Viggiano D, Vallone D, Sadile A (2004): Dysfunctions in dopamine systems and ADHD: Evidence from animals and modeling. Neural Plast 11: 97-114.

159. Renteria R, Baltz ET, Gremel CM (2018): Chronic alcohol exposure disrupts top-down control over basal ganglia action selection to produce habits. Nat Commun 9: 1-11.

160. Shan Q, Christie MJ, Balleine BW (2015): Plasticity in striatopallidal projection neurons mediates the acquisition of habitual actions. Eur J Neurosci 42: 2097-2104.

161. Gremel CM, Chancey JH, Atwood BK, Luo G, Neve R, Ramakrishnan C, et al. (2016): Endocannabinoid Modulation of Orbitostriatal Circuits Gates Habit Formation. Neuron 90: 13121324.

162. Wang Z, Ph D, Maia T V, Ph D, Marsh R, Ph D, et al. (n.d.): T h e N e u ra $1 \mathrm{C}$ irc u its T h a t G e $\mathrm{n}$ 
e ra te $\mathrm{T}$ ic $\mathrm{s}$ in To u re tte 's $\mathrm{S}$ y n d ro $\mathrm{m}$ e. 1326-1337.

163. Ahmari SE, Douglass NL, Kheirbek MA, Simpson HB, Gordon JA, Hen R, et al. (2013): Repeated cortico-striatal stimulation generates persistent OCD-like behavior. Science (80- ) 340: 1234-1239.

164. Burguière E, Monteiro P, Feng G, Graybiel AM (2013): Optogenetic Stimulation of Lateral Orbitofronto-Striatal Pathway Suppresses Compulsive Behaviors. Science (80- ) 340: 1243-1246.

165. Clarke HF, Robbins TW, Roberts AC (2008): Lesions of the medial striatum in monkeys produce perseverative impairments during reversal learning similar to those produced by lesions of the orbitofrontal cortex. J Neurosci 28: 10972-10982.

166. Castañé Anna A, Theobald DEH, Robbins TW (2010): Selective lesions of the dorsomedial striatum impair serial spatial reversal learning in rats. Behav Brain Res 210: 74-83.

167. Manning EE, Dombrovski AY, Torregrossa MM, Ahmari SE (2019): Impaired instrumental reversal learning is associated with increased medial prefrontal cortex activity in Sapap3 knockout mouse model of compulsive behavior. Neuropsychopharmacology 44: 1494-1504.

168. Corbit VL, Manning EE, Gittis AH, Ahmari SE (2019): Strengthened inputs from secondary motor cortex to striatum in a mouse model of compulsive behavior. J Neurosci 39: 2965-2975.

169. Morein-Zamir S, Fineberg NA, Robbins TW, Sahakian BJ (2010): Inhibition of thoughts and actions in obsessive-compulsive disorder: Extending the endophenotype? Psychol Med 40: 263-272.

170. Jentsch JD, Pennington ZT (2014): Reward, interrupted: Inhibitory control and its relevance to addictions. Neuropharmacology 76: 479-486.

171. Dillon DG, Pizzagalli DA (2007): Inhibition of action, thought, and emotion: A selective neurobiological review. Appl Prev Psychol 12: 99-114.

172. Jasinska AJ, Chen BT, Bonci A, Stein EA (2015): Dorsal medial prefrontal cortex (MPFC) circuitry in rodent models of cocaine use: Implications for drug addiction therapies. Addict Biol 20: 215-226.

173. Jonkman S, Mar AC, Dickinson A, Robbins TW, Everitt BJ (2009): The Rat Prelimbic Cortex Mediates Inhibitory Response Control But Not the Consolidation of Instrumental Learning. Behav Neurosci 123: 875-885.

174. Narayanan NS, Laubach M (2006): Top-Down Control of Motor Cortex Ensembles by Dorsomedial Prefrontal Cortex. Neuron 52: 921-931.

175. Ishikawa A, Ambroggi F, Nicola SM, Fields HL (2008): Contributions of the amygdala and medial prefrontal cortex to incentive cue responding. Neuroscience 155: 573-584.

176. Murphy ER, Dalley JW, Robbins TW (2005): Local glutamate receptor antagonism in the rat prefrontal cortex disrupts response inhibition in a visuospatial attentional task. Psychopharmacology (Berl) 179: 99-107.

177. Bari A, Mar AC, Theobald DE, Elands SA, Oganya KCNA, Eagle DM, Robbins TW (2011): Prefrontal and monoaminergic contributions to stop-signal task performance in rats. J Neurosci 31: 9254-9263.

178. Miao S, Han J, Gu Y, Wang X, Song W, Li D, et al. (2017): Reduced prefrontal cortex activation in children with attention-deficit/hyperactivity disorder during go/no-go task: A functional nearinfrared spectroscopy study. Front Neurosci 11: 1-7.

179. Fryer SL, Tapert SF, Mattson SN, Paulus MP, Spadoni AD, Riley EP (2007): Prenatal alcohol 
exposure affects frontal-striatal BOLD response during inhibitory control. Alcohol Clin Exp Res 31: $1415-1424$.

180. Ragozzino ME, Detrick S, Kesner RP (1999): Involvement of the prelimbic-infralimbic areas of the rodent prefrontal cortex in behavioral flexibility for place and response learning. J Neurosci 19: $4585-4594$.

181. Joel D, Weiner I, Feldon J (1997): Electrolytic lesions of the medial prefrontal cortex in rats disrupt performance on an analog of the Wisconsin Card Sorting Test, but do not disrupt latent inhibition: Implications for animal models of schizophrenia. Behav Brain Res 85: 187-201.

182. Floresco SB, Block AE, Tse MTL (2008): Inactivation of the medial prefrontal cortex of the rat impairs strategy set-shifting, but not reversal learning, using a novel, automated procedure. Behav Brain Res 190: 85-96.

183. Chen BT, Yau H-J, Hatch C, Kusumoto-Yoshida I, Cho SL, Hopf FW, Bonci A (2013): Rescuing cocaine-induced prefrontal cortex hypoactivity prevents compulsive cocaine seeking. Nature 496: 359-62.

184. Pascoli V, Terrier J, Espallergues J, Valjent E, O’connor EC, Lüscher C (2014): Contrasting forms of cocaine-evoked plasticity control components of relapse. Nature 509: 459-464.

185. Ma T, Cheng Y, Roltsch Hellard E, Wang X, Lu J, Gao X, et al. (2018): Bidirectional and longlasting control of alcohol-seeking behavior by corticostriatal LTP and LTD. Nat Neurosci 21: 373 383.

186. Pascoli V, Hiver A, Van Zessen R, Loureiro M, Achargui R, Harada M, et al. (2018): Stochastic synaptic plasticity underlying compulsion in a model of addiction. Nature 564: 366-371.

187. Albin RL, Young AB, Penney JB (1989): The functional anatomy of basal ganglia disorders. Trends Neurosci. https://doi.org/10.1016/0166-2236(89)90074-X

188. DeLong MR (1990): Primate models of movement disorders of basal ganglia origin. Trends in Neurosciences. https://doi.org/10.1016/0166-2236(90)90110-V

189. Cui G, Jun SB, Jin X, Pham MD, Vogel SS, Lovinger DM, Costa RM (2013): Concurrent activation of striatal direct and indirect pathways during action initiation. Nature 494: 238-242.

190. Parker JG, Marshall JD, Ahanonu B, Wu YW, Kim TH, Grewe BF, et al. (2018): Diametric neural ensemble dynamics in parkinsonian and dyskinetic states. Nature, vol. 557.

https://doi.org/10.1038/s41586-018-0090-6

191. Dobbs LKK, Kaplan ARR, Lemos JCC, Matsui A, Rubinstein M, Alvarez VAA (2016): Dopamine Regulation of Lateral Inhibition between Striatal Neurons Gates the Stimulant Actions of Cocaine. Neuron 90: 1100-1113.

192. Lemos JC, Friend DM, Kaplan AR, Shin JH, Rubinstein M, Kravitz A V., Alvarez VA (2016): Enhanced GABA Transmission Drives Bradykinesia Following Loss of Dopamine D2 Receptor Signaling. Neuron 90: 824-838.

193. Mela M, Okpalauwaekwe U, Anderson T, Eng J, Nomani S, Ahmed A, Barr AM (2018): The utility of psychotropic drugs on patients with Fetal Alcohol Spectrum Disorder (FASD): a systematic review. Psychiatry Clin Psychopharmacol 28: 436-445.

194. Cavanaugh SE (2015): A transition in fetal alcohol syndrome research: The shift from animal modeling to human intervention. Alcohol Alcohol 50: 251-255. 
195. Liang J, Shen Y, Shao XM, Scott MB, Ly E, Wong S, et al. (2014): Dihydromyricetin prevents fetal alcohol exposure-induced behavioral and physiological deficits: The roles of GABAA receptors in adolescence. Neurochem Res 39: 1147-1161.

196. Tunc-Ozcan E, Wert SL, Lim PH, Ferreira A, Redei EE (2018): Hippocampus-dependent memory and allele-specific gene expression in adult offspring of alcohol-consuming dams after neonatal treatment with thyroxin or metformin. Mol Psychiatry 23: 1643-1651.

197. Wilcoxon JS, Kuo AG, Disterhoft JF, Redei EE (2005): Behavioral deficits associated with fetal alcohol exposure are reversed by prenatal thyroid hormone treatment: A role for maternal thyroid hormone deficiency in FAE. Mol Psychiatry 10: 961-971.

198. Niemi WD, Slivinski K, Audi J, Rej R, Carpenter DO (1996): Propylthiouracil treatment reduces long-term potentiation in area CA1 of neonatal rat hippocampus. Neurosci Lett 210: 127-129.

199. Taylor MA, Swant J, Wagner JJ, Fisher JW, Ferguson DC (2008): Lower thyroid compensatory reserve of rat pups after maternal hypothyroidism: Correlation of thyroid, hepatic, and cerebrocortical biomarkers with hippocampal neurophysiology. Endocrinology 149: 3521-3530.

200. Medina AE, Krahe TE, Ramoa AS (2006): Restoration of neuronal plasticity by a phosphodiesterase type 1 inhibitor in a model of fetal alcohol exposure. J Neurosci 26: 1057-1060.

201. Thomas JD, Garrison M, O’Neill TM (2004): Perinatal choline supplementation attenuates behavioral alterations associated with neonatal alcohol exposure in rats. Neurotoxicol Teratol 26: $35-45$.

202. Thomas JD, Biane JS, O’Bryan KA, O’Neill TM, Dominguez HD (2007): Choline supplementation following third-trimester-equivalent alcohol exposure attenuates behavioral alterations in rats. Behav Neurosci 121: 120-130.

203. Monk BR, Leslie FM, Thomas JD (2012): The effects of perinatal choline supplementation on hippocampal cholinergic development in rats exposed to alcohol during the brain growth spurt. Hippocampus 22: 1750-1757.

204. Lester DB, Rogers TD, Blaha CD (2010): Acetylcholine-dopamine interactions in the pathophysiology and treatment of CNS disorders. CNS Neurosci Ther 16: 137-162.

205. Partridge JG, Apparsundaram S, Gerhardt GA, Ronesi J, Lovinger DM (2002): Nicotinic Acetylcholine Receptors Interact with Dopamine in Induction of Striatal Long-Term Depression. $J$ Neurosci 22: 2541-2549.

206. Savage DD, Rosenberg MJ, Wolff CR, Akers KG, El-Emawy A, Staples MC, et al. (2010): Effects of a novel cognition-enhancing agent on fetal ethanol-induced learning deficits. Alcohol Clin Exp Res 34: 1793-1802.

207. Varaschin RK, Akers KG, Rosenberg MJ, Hamilton DA, Savage DD (2010): Effects of the cognition-enhancing agent ABT-239 on fetal ethanol-induced deficits in dentate gyrus synaptic plasticity. J Pharmacol Exp Ther 334: 191-198.

208. Gozes I, Divinski I, Piltzer I (2008): NAP and D-SAL: neuroprotection against the $\beta$ amyloid peptide (1-42). BMC Neurosci 9: 1-5.

209. Vink J, Auth J, Abebe DT, Brenneman DE, Spong CY (2005): Novel peptides prevent alcoholinduced spatial learning deficits and proinflammatory cytokine release in a mouse model of fetal alcohol syndrome. Am J Obstet Gynecol 193: 825-829. 
210. Toso L, Poggi SH, Roberson R, Woodard J, Park J, Abebe D, Spong CY (2006): Prevention of alcohol-induced learning deficits in fetal alcohol syndrome mediated through NMDA and GABA receptors. Am J Obstet Gynecol 194: 681-686.

211. Incerti M, Vink J, Roberson R, Wood L, Abebe D, Spong CY (2010): Reversal of alcohol-induced learning deficits in the young adult in a model of fetal alcohol syndrome. Obstet Gynecol 115: 350356.

212. Vaglenova J, Pandiella N, Wijayawardhane N, Vaithianathan T, Birru S, Breese C, et al. (2008): Aniracetam reversed learning and memory deficits following prenatal ethanol exposure by modulating functions of synaptic AMPA receptors. Neuropsychopharmacology 33: 1071-1083.

213. Christie BR, Swann SE, Fox CJ, Froc D, Lieblich SE, Redila V, Webber A (2005): Voluntary exercise rescues deficits in spatial memory and long-term potentiation in prenatal ethanol-exposed male rats. Eur J Neurosci 21: 1719-1726.

214. Brice J, Mclellan L (1980): Suppression of Intention Tremor By Contingent Deep-Brain Stimulation. Lancet 315: 1221-1222.

215. Terraneo A, Leggio L, Saladini M, Ermani M, Bonci A, Gallimberti L (2016): Transcranial magnetic stimulation of dorsolateral prefrontal cortex reduces cocaine use: A pilot study. Eur Neuropsychopharmacol 26: 37-44.

216. Mayberg HS, Lozano AM, Voon V, Mcneely HE, Seminowicz D, Hamani C, et al. (2005): Deep Brain Stimulation for Treatment-Resistant Depression ing electrical stimulation of the subgenual cingulate. Neuron 45: 651-660.

217. Boroda E, Krueger AM, Bansal P, Schumacher MJ, Roy A V., Boys CJ, et al. (2020): A randomized controlled trial of transcranial direct-current stimulation and cognitive training in children with fetal alcohol spectrum disorder. Brain Stimul 13: 1059-1068. 